\title{
MEASURING HEALTH INSURANCE BENEFITS: THE CASE OF PEOPLE WITH DISABILITIES
}

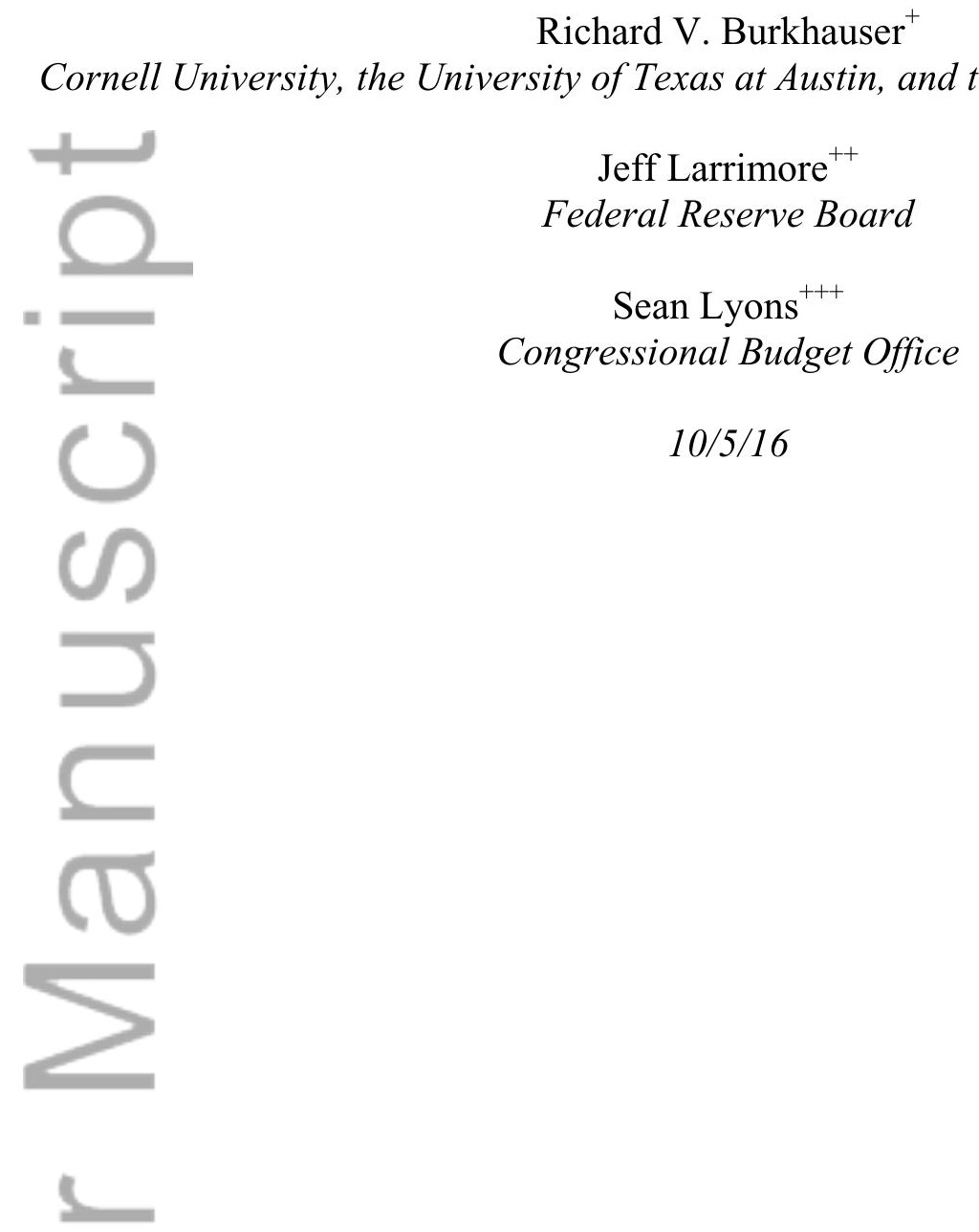

Support for this research from the Employment Policy and Measurement Rehabilitation Research and Training Center at the University of New Hampshire, which is funded by the National Institute for Disability and Rehabilitation Research (NIDRR, grant no. H133B100030) is cordially acknowledged. The analysis and conclusions set forth in this paper are those of the authors and do not indicate concurrence by the Congressional Budget Office, the Federal Reserve Board of Governors, other members of their staffs.

+259 Martha Van Rensselaer Hall, Cornell University, Ithaca, NY, 15853. Phone: 607-225-2097. E-mail:rvb1@cornell.edu

This is the author manuscript accepted for publication and has undergone full peer review but has not been through the copyediting, typesetting, pagination and proofreading process, which may lead to differences between this version and the Version of Record. Please cite this article as doi: 10.1111/coep.12213

This article is protected by copyright. All rights reserved. 
${ }^{++}$CORRESPONDING AUTHOR. $20^{\text {th }}$ and Constitution Ave. NW, Federal Reserve Board of Governors, Washington, DC 20551. Phone: 202-973-7315.E-mail: jeff.larrimore@frb.gov

${ }^{+++}$Ford House Office Building, $4^{\text {th }}$ Floor, $2^{\text {nd }}$ and D St SW, Washington, DC 20515. Phone: 202226-1716. E-mail: sean.lyons@cbo.gov

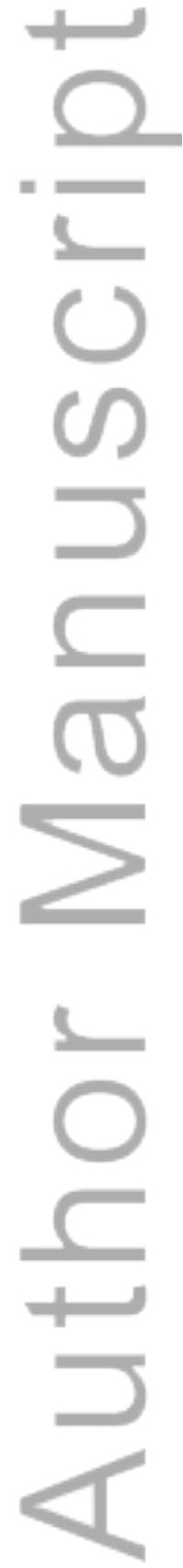




\begin{abstract}
Since 2012 the Congressional Budget Office has included an estimate of the market value of government-provided health insurance coverage in its measures of household income. We follow this practice for both public and private health insurance to capture the impact of greater access to government-provided health insurance for working-age people with disabilities, whose market value rose in 2010 dollars from $\$ 11.7 \mathrm{~B}$ in 1980 to $\$ 114.3 \mathrm{~B}$ in 2012 . We then consider the more general implications of incorporating estimates of the market price of insurance, equivalent to that provided by the government, into policy analyses in a post-Affordable Care Act world.

JEL codes: D31, H24, I18, J31
\end{abstract}

Keywords: Health Insurance, Medicare and Medicaid, Disabilities, Resource Measurement

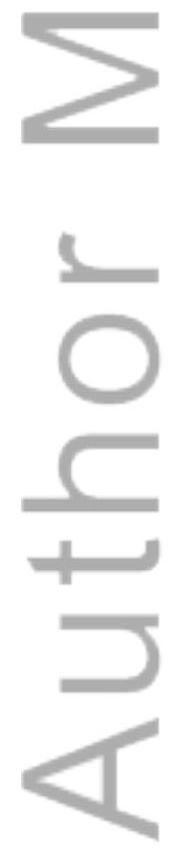


A crucial aspect of many recent policy debates in the United States focuses on the distribution and redistribution of financial resources. This can be seen in recent discussions of healthcare policies (Aaron and Burtless 2014), tax policies (Nunns, Eng, and Austin 2014), and income support policies (MaCurdy 2015). However, for such discussions to be meaningful, it is necessary to first establish an accurate assessment of how resources are currently distributed. To this end, starting in 2012 the Congressional Budget Office (CBO) has included an estimate of the market value of government-provided health insurance coverage in its measure of household resources (CBO 2012, 2013). However, there is considerable debate in the academic literature over the importance of including the market value of health insurance (i.e., the cost to employers and government of providing health insurance) in measures of economic resources and their distribution. (See Burkhauser, Larrimore and Simon 2013, for a discussion of this debate.) A small academic literature shows that the inclusion of the market value of health insurance impacts resource levels, but has little effect on trends outside of the bottom of the distribution (Burtless and Svaton 2010; Burkhauser, Larrimore and Simon 2013; Burtless and Milusheva 2013; Sommers and Oellerich 2013; Armour, Burkhauser, and Larrimore 2014). However, placing a resource value on health insurance may be more important for specific segments of the population than it is for the whole population and to date no analyses have been done on its importance on these segments of the population. Here we focus on an obvious oneworking-age people with self-reported work activity limitations (i.e., working-age people with disabilities). In doing so, we assess the impact of the new $\mathrm{CBO}$ approach of including the market value of government-provided health insurance in measures of economic resources. 
Following this approach to valuing health insurance, we demonstrate the impact that increased access to private and public health insurance has had on the observed economic resources of individuals with disabilities since 1980, both absolutely and relative to the rest of the workingage population. This growth in the share of resources of those with disabilities that are devoted to medical costs matters for a number of policy debates, including discussions of the distribution of resources across population groups as well as discussions over how program rules affect the behavior of those receiving these benefits who may consider entering the labor market or those who are considering applying for these benefits.

Using our findings as an example, we then discuss the merits of valuing health insurance coverage as an economic resource based on its price in the market place, and consider how the Affordable Care Act (ACA) fundamentally changes the market values under this approach.

\section{BACKGROUND ON THE WORKING-AGE POPULATION WITH DISABILITIES}

The working-age population (aged 18-64) with disabilities that we focus on in this paper is important both as a share of the overall population ( $8.2 \%$ of working-age adults reported having a work activity limitation in 2011) and as a share of government expenditures. Using aggregate expenditures, Livermore, Stapleton, and O'Toole (2011) document that $12 \%$ of all federal government expenditures focused on working-age people with disabilities in 2008. This amounted to $\$ 357.3$ billion, an increase of $30.6 \%$ in real terms from 2002 . Federal health care expenditures (primarily Medicare and Medicaid) made up $\$ 169.1$ billion of these expenditures ( $47.3 \%$ of the total) in 2008 , nearly equaling the $\$ 169.8$ billion going towards income 
maintenance expenditures (primarily Social Security Disability Insurance (DI) and Supplemental Security Insurance (SSI)).

In Figure 1 we provide a first look at the potential importance of capturing the market value of Medicare and Medicaid (measured in 2010 dollars) in a measure of the resources of working-age people with disabilities. Using individual-level data from the Current Population Survey for income years 1980 through 2012 we capture the total value of DI and SSI cash benefits received by working-age people with disabilities and their households. We then compare the total values of these DI and SSI cash benefits, which are included in standard measures of government transfers, with the total market value of Medicare and Medicaid received by working-age people with disabilities and their households through the DI and SSI programs, which is not generally captured in standard measures of government transfers.

There has been substantial growth in the value of both these cash transfers (DI and SSI) and Public Health Insurance (Medicare and Medicaid) since 1980, but much more so for Medicare and Medicaid. As a result, the share of government transfers to those with disabilities that came through these health insurance programs increased from 23.29\% (\$11.7 Billion) of transfers to those with disabilities in 1980 to $53.15 \%$ (\$114.3 Billion) in $2012 .{ }^{1}$

Figure 2 (Panel A) shows that the growth in DI and SSI benefits (measured in 2010 dollars) received by working-age people with disabilities over the 1982 to 2012 period was, in part, caused by substantial increases in the take-up rates of those receiving either DI or SSI

\footnotetext{
${ }^{1}$ While our aggregate values are somewhat different from those Livermore et al. (2011) report, our trends are similar, and, more importantly, because our aggregate values come from individual record files we are able to show how these benefits are distributed across the income distribution. See the Appendix for a fuller discussion of the differences in our estimation methods and those of Livermore et al. (2011).
} 
benefits or both. Take-up rates (based on three-year moving averages with 1982 being the mean value of 1980-1982) increased from $28 \%$ in 1982 to $49 \%$ in 2012. Employer-provided health insurance coverage (Private HI) declined substantially for working-age people with disabilities as their employment declined over this period, but this decline was more than offset by the rise in their access to government-provided Medicare and Medicaid coverage (Public HI) either via DI or SSI or other federal government programs. There was an increase in dual eligibles (persons covered by both Medicare and Medicaid) as well. As a result the share of working-age people with disabilities who are uninsured fell from $25.5 \%$ in 1982 to $14.9 \%$ in 2012. In comparison, the share of working-age people without disabilities who are uninsured was $21.9 \%$ in 2012 , slightly above the 20.7\% who were uninsured in 1982 (See Figure 1A in the appendix).

It is possible to estimate the relative importance of the change in take-up rates of public health insurance by those with disabilities on the program spending reported in Figure 1. To do so we hold spending per beneficiary and the share of the population reporting a disability constant at their 1982 levels but allow the share of those with a disability who take-up public health insurance to change. Doing so, we observe that $23 \%$ of the increase in disability-based health insurance spending reported in Figure 1 is due to increases in take-up rate.

Figure 2 (Panel B) shows that not including the market value of health insurance will also miss its growing resource value to working-age people with disabilities who have this coverage. It reports the median market value to recipients in this population of private employer-provided health insurance (Private $\mathrm{HI}$ ) as well as the market values of Medicare, Medicaid, and the combined market value to those covered by both these government-provided programs (dual 
eligibles). In the working-age population with disabilities, the median market value of each of these government-provided health insurance programs for recipients now exceeds the median cash value of DI and/or SSI benefits for those now receiving them. Furthermore, each of these median health insurance market values far exceeds the median employer contribution to employer-provided health insurance (Private HI) to those with disabilities that it covers.

$=$ Using a symmetric approach to that used above to observe that $23 \%$ of the increase in disability-based health insurance spending resulted from changes in take-up rates, we can approximate the extent to which the increased value per-recipient of this government-provided health insurance coverage resulted in the increased spending. When doing so, we observe that $46 \%$ of the increase in public health insurance spending on those with disabilities resulted from increases in spending per beneficiary. The remaining $30 \%$ of the increase came from an increase in the number of individuals reporting a disability.

Measures of "income" that do not include this resource will not only miss the growth in access to health insurance and its market value to those covered by this insurance but will also greatly understate the role that government-provided transfers (both in-cash and in-kind) play in increasing the economic resources of working-age people with disabilities. This is the case in absolute terms and also relative to working-age people without disabilities. (As shown in Figure 1A in the Appendix, working-age adults without disabilities did not experience the same level of increases in either insurance rates or in the median market value of that insurance.)

\section{DATA AND METHODS}


We explore the impact of including the market value of health insurance and other government transfers on the trends in economic resources of people with and without disabilities by comparing four alternative measures of income in the economics literature. We do so with the public-use March Current Population Survey (CPS) for income years 1980 to 2012 and supplement it with cell-means for top-coded incomes from Larrimore et al. (2008). The CPS $=$ includes Census Bureau estimates of the market value of employer- and government-provided health insurance, and is the only data set that provides consistent information on the economic resources of persons with disabilities since 1981 (income year 1980). $\underline{\text { Identification of Working-Age Persons with Disabilities }}$

We focus on working-age (aged 18 to 64 ) people who self-report having a work activity limitation. Respondents are asked if they have a health problem or disability which prevents work or which limits the kind or amount of work. Previous research has shown that this question is a good proxy for disability status. Benítez-Silva et al. (2004) find that self-reported work limitation responses are an unbiased indicator of DI eligibility decisions; Stern (1989) finds that the measure is close to exogenous, and Bound and Burkhauser (1999) find that it identifies populations with substantial differences in health status. Burkhauser et al. (2002) similarly argue that this question in the CPS can be reliably used to monitor trends in the outcomes of those with disabilities. This question is considered of value even in the context of other functional limitation questions, as Burkhauser, Houtenville, and Tennant (2014) and Burkhauser et al. (2015) observe that including responses to a work limitation question with those from the six-question sequence for capturing the population with disabilities (established by the U.S. Department of Health and 
Human Services within the Affordable Care Act of 2010) would better capture those receiving

DI and disability-related SSI benefits in the CPS data than the six-question sequence alone.

\section{$\underline{\text { Income and resource measures }}$}

Market income (definition 1) includes cash income from all private income sources.

Piketty and Saez (2003) and others in the top income literature use this measure of income but do so primarily with income tax records data (See: Atkinson, Piketty, and Saez 2011, for a review of this literature).

The second measure is market and cash transfer income (definition 2), which includes cash income from all private and government sources in the CPS. This was the most commonly used income measure through the early 2000s. (See: Atkinson and Brandolini 2001 and Gottschalk and Smeeding 1997, for early reviews of this literature.) For more recent examples, see Gottschalk and Danziger (2005), Daly and Valletta (2006), and Blank (2011). It continues to be used by the Census Bureau (DeNavas Walt and Proctor 2015) and for those tracking the resources available to those with and without disability (See for example: Houtenville et al. 2009; Burkhauser and Daly 2011; and Stapleton 2011).

The third measure (definition 3) is disposable income, which includes cash income from all private and government sources in the CPS plus some in-kind transfers (SNAP, housing subsidies, and school lunches) as well as tax credits minus federal and state income taxes. The CBO (2011) used a conceptually similar measure of income prior to $2012 .^{2}$ A disposable income measure is also preferred by the OECD (d'Ercole and Förster 2012) in its international studies of

${ }^{2}$ Prior to 2012, the CBO used an income measure, which included the Census' estimated fungible value of Medicare and Medicaid. In subsequent years the CBO used the Census' estimated market value of Medicare and Medicaid. 
income. In constructing this measure, the Census Bureau imputes the market value of SNAP (food stamps), subsidized housing, and school lunches on an annual basis. We include the Census imputed values of the market value of these in-kind government transfers. Each of these in-kind transfers are included as resources in the Census Bureau's Supplemental Poverty Measure (Interagency Technical Working Group 2010).

We also impute the value of tax credits and tax liabilities using NBER TaxSim 9.0 (see Feenberg and Coutts 1993 for more information on the TaxSim program). Tax liabilities include federal and state income tax liabilities as well as FICA and SECA taxes based on the tax laws in effect in each year and also include refundable and non-refundable tax credits including the Earned Income Tax Credit (EITC) and Child Tax Credit (CTC). To better reflect the tax filing units from which actual tax credits and liabilities are determined, we construct tax units within each household prior to imputing tax credits and liabilities using the Burkhauser, Larrimore and Simon (2012) procedure, which is based on the same assumptions Piketty and Saez (2003) use to create their tax units.

The fourth measure, which we will call comprehensive resources (definition 4), includes all the resources included in disposable income plus the market value of employer-sponsored health insurance and government-provided (Medicare and Medicaid) health insurance. It is the most complete of the four yearly measures of the flow of resources available to individuals and their households.

In constructing this fourth measure, we note that in-kind benefits in the form of health insurance, like all other in-kind benefits, have value to individuals—otherwise employees would 
negotiate higher wages in exchange for foregoing health insurance and government actors would have a strong incentive to replace Medicaid and Medicare benefits with cash transfer programs or lower taxes. Measures that exclude the value of health insurance as a resource undervalue its worth by effectively placing a zero value on access to this resource. This exclusion will not only understate the level of household resources but also their trend, as the market value of health insurance has increased in both absolute terms and as a share of wage compensation or as a share of all government transfers to households. It is for these reasons that the CBO began including the marketvalue of health insurance in its measures of income stating in 2012.

\section{Determining the market value of health insurance}

The market value is based on the Census Bureau's imputation of the value of health insurance, which is also used by the CBO (2012). The insurance values are assigned to individuals who report in the CPS that they were insured by a given type of insurance in the past year. While we follow the approach of the $\mathrm{CBO}$, and others, in accepting the Census Bureau values as accurate, there is evidence that individuals underreport health insurance coverage in the CPS data, which may lead to an understatement of health insurance resources for those who erroneously report that they are uninsured (see Pascale, Roemer, and Resnick 2007, Daverns et al. 2009, and Pascale, Boudreaux, and King 2016 for discussions of this underreporting).

For those reporting employer-sponsored health insurance, the Census Bureau imputes the value of benefits by first determining whether the individual is covered by an employersponsored plan and whether the employer paid for all, part, or none of the plan premium. Next, persons in the March CPS are statistically matched to persons in the National Medical Care 
Expenditure Survey or Medical Expenditure Panel Survey (depending on survey year) based on several demographic characteristics to impute the cash value of employer contributions. The Census Bureau uses this imputed value as its measure of the market value of private insurance for covered workers. Individual expenditures on employer-sponsored health insurance plan premiums or expenditures on small-group/individual market health plans come from other income sources and are not included as income.

For those covered by government-subsidized health insurance (Medicare and Medicaid), the Census Bureau determines the average government cost of providing Medicare and Medicaid to those reporting that they have this insurance by state and risk class. This amount reflects the net outlays after subtracting Supplemental Medical Insurance (SMI) premium payments made by Medicare beneficiaries for Part B and Part D insurance, since these premium payments are paid by the beneficiary rather than the government. The two risk classes for Medicare are aged and disabled. The four risk classes for Medicaid are aged, disabled, children, and adults. ${ }^{3}$ Thus, the imputed average cost of government-provided health insurance varies by state and the government insurance pool from which beneficiaries access it.

In determining the market value of Medicaid and Medicare, for individuals who qualify for both programs (dual eligible), we follow the Census Bureau's approach and estimate the

\footnotetext{
${ }^{3}$ The Medicare and Medicaid risk classes reflect the channel through which benefits were accessed. The Medicare risk class "aged" applies to all persons on Medicare aged 65 or older. The Medicare risk class "disabled" applies to all persons accessing Medicare benefits through the SSDI program. The Medicaid risk class "children" applies to children accessing Medicaid benefits through either traditional Medicaid or a state's Children's Health Insurance Program (CHIP). The Medicaid risk class "adults" applies to all adults under the age of 65 accessing Medicaid benefits. The Medicaid risk class "aged" applies to all persons accessing Medicaid aged 65 or older. Lastly, the Medicaid risk class "disabled" applies to all persons accessing Medicaid benefits due to their qualification for SSI benefits. See Census Bureau $(1988,1993)$ for full discussions of the origins of their estimations of the market value of Medicare and Medicaid.
} 
resource value of their health insurance as the combined cost of insurance from each program. CBO (2012) and Armour, Burkhauser, and Larrimore (2014) do the same. This assumes that the total value of the insurance dual-eligible individuals receive is not only greater to them than the value for those insured under only one of these programs but is greater by the average cost of the other program. This may overstate this value to the degree that there is overlap in coverage. But it might understate it to the degree that dual-eligible individuals have higher than average medical expenses relative to those who are only covered by one program. So this value still may be less than the cost dual-eligible individuals incur if they purchase equivalent insurance on the private market.

Although the Census Bureau's imputation is the standard for valuing the market value for health insurance, and we are unaware of any researchers who include the market value of both private and public health insurance as a resource in other ways, it is not the only potential approach. In particular, an important aspect of this valuation approach is whether the risk-pools are defined accurately and whether they reflect the way that individuals would be grouped in the health insurance market. Were the Census Bureau to use broader risk-pools, such that all Medicaid recipients collectively are in a single risk-pool and all Medicare recipients are in a single risk-pool, this would reduce the estimated market value of health insurance to those with disabilities. However, recognizing that prior to the passage of the Affordable Care Act older individuals and those with disabilities would pay more for private insurance (if they could obtain it at all), we argue that the Census Bureau's approach of assigning risk-pools based on both age and health status is reasonable. Using a single risk-pool would understate the market value of 
insurance for older or disabled individuals who would be charged a higher price for this insurance on the private market.

As is discussed in more detail in Section IV, however, the health insurance market was fundamentally changed on January 1, 2014 when the Affordable Care Act of 2010's prohibition of insurance rating on health status (and to a more limited degree on ratings based on age) was implemented. In such a market, the Census Bureau's current system of imputations and the CBO estimates of market value based on them will no longer reflect the way that individuals on Medicare and Medicaid are grouped in the health insurance market. Thus beginning in income year 2014 the market value of Medicare and Medicaid should change to reflect the new community rated risk-pools required in the private insurance market when measuring the economic resources of people receiving this coverage.

\section{$\underline{\text { Unit of Analysis }}$}

Our unit of analysis is the individual. To account for economies of scale in household consumption, household resources are divided by the square root of the number of persons in the household. ${ }^{4}$ This size adjustment is common in US and international research studies of income trends and inequality (for example, see Gottschalk and Smeeding 1997; Atkinson and Brandolini 2001; d'Ercole and Förster 2012; Ruggles 1990).

Inflation

-All dollar values are adjusted to 2010-dollar amounts using the Consumer Price Index Research Series (CPI-U-RS) (Stewart and Reed 1999). This follows previous research

${ }^{4}$ While size-adjusted income is an individual-level value, it can easily be converted to consider the income of a family of four by doubling the size-adjusted income values presented in the paper. 
considering both population-level income trends (DeNavas Walt and Proctor 2015) and those measuring the relative resources of those with and without disabilities (Burkhauser and Larrimore 2009).

While we follow the standard practice of the CBO (2012) and other income researchers of adjusting for inflation using a uniform inflation measure, we acknowledge that the inflation $=$ rates for all goods and services are not uniform. To the extent that some individuals consume a larger fraction of goods, which have increased in price faster (slower) than the general rate of inflation, the uniform measure may overstate (understate) their actual change in resources. The uneven nature of rising costs are not unique to health care, but they are particularly acute in that sector since its prices have risen faster than general inflation in recent decades. For example, individuals with disabilities and the elderly, who both have a larger fraction of their resources devoted to health care costs than the general population, will likely appear to have a greater increase in their resources from a uniform measure than the general population. It is similarly true, however, that parents and college-age individuals will be more impacted by inflation in the education sector, and individuals who spend a disproportionately large fraction of their income on housing will be more impacted by inflation in the housing sector. Hence, the potential for individuals with different consumption bundles to be impacted differently by inflation exists regardless of the income measure used and this represents a broader challenge for any analysis of long-term trends across population groups. ${ }^{5}$ Nevertheless, readers are encouraged to consider

\footnotetext{
${ }^{5}$ The impact of inflation and whether medical cost increases reflect changes to the cost or quality of care is also sometimes conflated with the value of employer- and government-provided health insurance. However, since rising costs are occurring in the health care sector generally, were it not for health insurance paid for by one's employer or
} 
this concern when evaluating trends in resources or well-being of population groups in this and all other studies.

\section{RESULTS}

Figure 3 reports the levels and trends in the median level of resources (in 2010 dollars) of working-age people with disabilities (Panel A) and without disabilities (Panel B) using our four alternative measures. A comparison of these four alternatives illustrates the importance of the measurement choices to the resources of the population reporting a disability.

The trend in market income of the median working-age person with disabilities follows, albeit with relatively little variation, the economic business cycle pattern over the first two full trough-to-trough business cycles (1983-1993-2004). ${ }^{6}$ It rises slightly from trough year 1983 through peak year 1989 before falling even lower by trough year 1993. It then rises to a 1999 high before falling to approximately its 1993 trough year level in trough year 2004. With the exception of a slight increase in 2006, it has fallen continuously since then, reaching a record low for the past 30 years in trough year 2011 before falling even further in 2012. Over the three full trough-to-trough business cycles that Panel A captures, median market income for working-age people with disabilities fell from $\$ 13,304$ in 1983 to $\$ 9,448$ in 2011 .

the government these rising costs would be paid for out of pocket. As such, the question of why health costs are rising is separate from the question of how health insurance should be valued. See Burkhauser et al. (2013) for a discussion of this issue and other issues related to estimating the value of health insurance.

${ }^{6}$ Trough years are defined as the last year in which median size-adjusted market income of all persons falls following a recession - 1983, 1993, 2004, and 2011 — and peak years are defined as the highest median market income year between these troughs - 1989, 2000, and 2007. With the exception of 1983, the median market income trough years follow the official NBER recession ending years - the shaded years in this figure. This is the case, because the major component of market income is labor earnings and it is a lag indicator of business recovery. 
Focusing exclusively on market income, however, will yield a misleading picture of the trend in economic resources for this population as the substantial drop in market income has been offset by increases in other sources of income. Median market and cash transfer income combined is not only higher in all years, but the growth of government cash transfers has increasingly mitigated the drop in market income over time. Median disposable income is slightly lower than market and cash transfer income in all years but this difference is smaller in later years. Over the three full trough-to-trough business cycles that Panel A captures, median disposable income rose from $\$ 17,529$ in 1983 to $\$ 18,347$ in 1993 to $\$ 19,989$ in 2004 before falling to $\$ 18,840$ in 2011 , for an overall increase of $7.5 \%$.

Prior to 2012, the disposable income series most closely represented the way that the $\mathrm{CBO}$, and others, measured economic resources. The market income plus cash transfers measure, similarly, represents the measure of economic resources that still is tracked by the U.S. Census Bureau (DeNavas Walt and Proctor 2014). However, both of these measures exclude the substantial economic resources that are provided to this population in the form of health insurance coverage. Including the market value of employer- and government-provided health insurance dramatically changes the trajectory of median "income" for this population.

In 1983 there is very little difference between our median disposable income measure and our median comprehensive resources measure that adds the market value of health insurance coverage to it. But the substantial increases since then in access to health insurance (Figure 2, Panel A) and in its median value to those it covers (Figure 2, Panel B) profoundly increases the gap between these two resource measures. The median of our comprehensive resources measure 
rises substantially over the first two business cycles. It peaks in 2005 before declining through 2008. With the coming of the Great Recession, the rise in the market value of health insurance begins to grow again and more than offsets the decline in other income, so that while median disposable income has fallen continuously since 2008, when the value of health insurance is added, median comprehensive resources including the value of health insurance increases slightly in 2009 and 2010 before falling slightly in subsequent years. That is, using our most complete resource measure we find that the economic resources available to the median person with disabilities have grown substantially over the past 30 years. Over the entire three-businesscycle period(1983-2011), median comprehensive resources including health insurance increased by $51 \%$ from $\$ 19,978$ to $\$ 30,137$. Figure 3, Panel B provides the same trends for working-age people without disabilities. As was the case in Panel A, our comprehensive resource measure has increased relative to our disposable income measure since 1983 but to a much smaller degree. The Income Gap between Working-Age People with and without Disabilities

From Panel A of Figure 3, it was apparent that the new approach to valuing health insurance has a dramatic impact on the measured absolute resources of working-age people with disabilities. Figure 4, in turn, focuses on its impact on their resources relative to those without disabilities by presenting the gap between the median resources of these two populations over the period 1980-2012. We derive these gaps by subtracting the median values by year for each definition in Figure 3 (Panel A) from their counterparts in Figure 3 (Panel B).

While the trends are the same for the first three series, the gap shrinks and the trends diverge when including the market value of health insurance in the resource measure. Over the 
three business cycles, the gap for this broader measure has declined from $\$ 7,636$ in 1983 to $\$ 6,164$ in 2011 . Hence, including the market value of health insurance in a fuller measure of resources substantially changes the picture of the relative resources of the population with disabilities. This is consistent with the growth in access to health insurance in the working-age population with disabilities over this period reported in Figure 1 and the increase in the values of government-provided health insurance over this period reported in Figure 2.

From Figures 3 and Figure 4, it is apparent that an increasing share of the resources working-age people with disabilities receive comes in the form of government-provided health insurance. When we systematically include these resources at their market value in our income measures, the absolute level of resources of those with disabilities rises and the income gap between those with and without disabilities narrows rather than increases over time.

This then raises the question of whether this more comprehensive approach for measuring resources appropriately reflects the way in which income and other economic resources are distributed in society. Since health insurance has a real cost to the government or to employers to provide to individuals, using a resource measure that includes the market value of health insurance is clearly better for aligning the measured resources of individuals with the costs of providing those resources. Of course, the greater level of resources accrued by those with disabilities also reflects their higher risk of requiring medical services - so even if there were no gap in the resources of those with and without disabilities it would not mean that they are equally well off. However, while the resource gap should not be taken as a reflection of their levels of well-being since health status undoubtedly plays a role in determining this, it does provide a 
more accurate reflection of the economic resources these populations have access to in policy discussions.

Additionally, using the market price of health insurance coverage has important implications for how policymakers think about the decisions of individuals in society. In particular, it provides a more accurate representation of the marginal costs associated with working-age people with disabilities forgoing access to disability-based government-provided insurance via employment. By incorporating the market price of Medicare and Medicaid as a resource for individuals, we pick up on key elements of the economic trade-off that those with disabilities consider when deciding whether to go back to work or make other choices that influence their access to these resources. As such, an analysis of economic decisions that exclude these resources could result in an incomplete picture of the actual trade-offs that such individuals face.

Change in the Characteristics of those in the Lowest Income Quintile of the Population

Figure 5, using this same fuller measure of comprehensive resources that includes the market value of health insurance, shows that the share of the working-age population with disabilities in the lowest quintile of the resource distribution also falls over time. In 1983 working-age people with disabilities made up 12.66 percent of the working-age population in the bottom income quintile of the population. Despite the fact that the prevalence of disability in the working-age population rose slightly from 7.24 percent to 8.17 percent, the share of people in the bottom quintile of the distribution who report a disability fell to 10.49 percent in 2011 . Over the 
same period, the percentage of people with disabilities in the middle three quintiles rose with little change in the top quintile.

Changing Portfolio of Income Sources for Persons with and without Disabilities

Table 1 provides additional insight into the growing importance of the market value of public health insurance in the income portfolios of working-age people with disabilities (measured in 2010 dollars). It estimates mean gross resources from private and all government sources including the market value of health insurance (our fourth measure of resources gross of taxes) for both working-age people with and without disabilities. It then divides this value into its nine non-overlapping income sources, including some that include the market value of health insurance, and shows how these shares change across the four trough years discussed above.

Table 1 focuses on pre-tax resources so that each income source is positive, in order to take advantage of the fact that mean income in any year can be divided into the sum of the mean of its sources when there are no negative sources of income. The first three sources (own labor earnings, the labor earnings of others in the household, and private non-labor income) represent total in-cash market income (definition 1). The next two (DI and/or SSI cash transfers and all other public cash transfers) represent gross in-cash government transfers. These first five sources of income make up definition 2. The next is government in-kind transfers excluding health insurance. The first six sources represent the total gross resources before taxes used in disposable income (definition 3). For the moment we do not consider the effect of taxes on this gross resource measure as is done in definition 3. The last three sources (the market value of employerprovided health insurance, the market value of government-provided health insurance to those 
receiving DI and/or SSI, and the market value of all other government-provided health insurance including Medicare and Medicaid accessed outside of DI and SSI) represent the market value of employer- and government-provided health insurance used in definition 4.

These shares sum to $100 \%$ in Table 1 . The final column reports the share of gross resources paid in taxes. We separate this negative value from our portfolio shares of gross resources in the other columns that sum to $100 \%$ to more easily isolate its impact.

For those without disabilities, market income provides the overwhelming share of pre-tax gross resources: $91.44 \%$ in 1983 . While this falls slightly across the other three trough years, market income remains the dominant source of income for working-age people without disabilities and is over $88 \%$ in each of the four years considered. In contrast, the share of pre-tax gross resources coming from market sources falls markedly for those with disabilities. In 1983, market income made up $70.80 \%$ of gross resources in 1983. By 2011 it is only slightly more than half of the gross resources of those with disabilities, $51.30 \%$.

Somewhat surprisingly, while DI and/or SSI cash transfers increases to some degree from 1983 to 2004 , this increase is entirely offset by declines in other government cash transfers so that total government in-cash transfers falls slightly. However, DI and/or SSI cash transfers then rise to $18.00 \%$ in 2011 . Aided by a slight increase in other government cash transfers, total government cash transfers rise to $21.70 \%$ in 2011 . But it is private and government health insurance whose share of gross resources increases the most for this population, from $8.82 \%$ in 1983 to $25.53 \%$ in 2011 . The rise in the share of gross resources coming from governmentprovided Medicare and Medicaid to DI and/or SSI recipients is driving this increase, representing 
less than 5\% of the gross resources of working-age people with disabilities in 1983 and over 18\% in 2011.

To provide some perspective on this finding, in 1983 government-provided Medicare and Medicaid to DI and/or SSI recipients was the sixth most important resource for working-age people with disabilities behind the market income from others' earnings, own labor earnings, private non-labor earnings, DI and/or SSI cash transfers, and all other public cash transfers respectively, In 2004 and 2011 it was the second most important resource, behind only the labor earnings of others in the household.

This finding on the increasing importance of Medicare and Medicaid as a resource for individuals with disabilities is important in the context of health care policy debates, as it suggests why some working-age people with disabilities, whose pre-existing conditions predicted they would require more expensive future medical services, but who could work to some degree, chose to move onto the DI/SSI rolls. As we showed in Figure 2B, for those who were eligible for both Medicaid and Medicare this value has been over $\$ 20,000$ per year since 2002. This provides a substantial incentive to apply for DI/SSI benefits and a disincentive to work part-time or enter the labor force once on the disability rolls, if by doing so those benefits are lost. This incentive would be completely missed were one to focus exclusively on either market income or disposable income excluding the value of health insurance.

\section{VALUING HEALTH INSURANCE AFTER THE ACA}

The justification that the $\mathrm{CBO}$, and others, use for valuing insurance at its market value using age and disability-status risk-pools is that this reflects the price that consumers would have 
to pay for an equivalent insurance policy in the open market. It is the reason we use this measure here. But is this the appropriate valuation for this coverage? From a budgetary standpoint, considering the value that individuals would pay for equivalent insurance on the private market is appealing. Were the government to not provide Medicare or Medicaid benefits to the population with disabilities, for example, and instead provided them with a cash payment to purchase insurance on their own - the market value reflects the amount of that cash payment that would need to be provided so that individuals could purchase similar coverage on their own. Additionally, if the insurance is generally not valued by its recipients at somewhere near the market value, why provided these in-kind benefits instead of cash? ${ }^{7}$

The age and disability status risk-pools were also appropriate prior to the Affordable Care Act, given that private insurers would charge different premiums based on these criteria. In most states insurers could adjust premiums (or deny insurance) to those with pre-existing conditions, so it was generally difficult and expensive for people with disabilities to obtain insurance on their own through the non-group market. We argue that the net outlays on health care expenses of Medicare and Medicaid for those in each risk-pools - which were used by the Census Bureau to impute the market value of these benefits - represent a reasonable approximation of the price individuals with a given set of characteristics would face in the private market.

\footnotetext{
${ }^{7}$ Some have argued, however, that the full market value may overstate the true value that individuals receive from health insurance benefits. For example, using the Oregon Health Insurance Experiment Finkelstein, Hendren, and Luttmer (2015) estimate that the welfare benefit to recipients of Medicaid is between $\$ 0.20$ and $\$ 0.40$ per dollar of spending. This result is partially derived from the fact that low-income individuals who do not receive Medicaid often receive uncompensated care from medical providers, which acts as a de facto form of insurance (see Garthwaite, Gross, and Notowidigdo 2015 for more details on this uncompensated care). Were we to use a fractional value along the lines suggested by Finkelstein et al. (2015), the trend in resources for those with disabilities would still be better than that observed when health insurance is valued at $\$ 0$, but it would offset some of the gains in resources for working-age people with disabilities that we discuss in this paper. Results using fractional valuations are available upon request from the authors.
} 
But, since January 1, 2014, under the Affordable Care Act of 2010, insurance companies are no longer permitted to adjust their premiums or deny coverage based on pre-existing conditions except in the case of grandfathered plans. This change in the law has made it less difficult and less expensive for people with disabilities to obtain insurance in the private market by lowering the market price for them, since they are now more easily able to enter an insurance pool of healthier members. It also means that the average government cost of providing Medicare and Medicaid to those who remain on DI/SSI (a group with a higher risk of health insurance services and hence a higher average insurance cost for group coverage than the exchange price) no longer represents the price they would face for equivalent market insurance. Reflecting this change in their insurance options, beginning in 2014 there now is a single market price that researchers can use to determine the value beneficiaries receive from government provided Medicaid and Medicare insurance. This price is the unsubsidized premium for an equivalent policy in the health insurance exchange. ${ }^{8}$ As was the case in our current estimation of the ex-ante value of government subsidies for health insurance, the SMI premiums that Medicare enrollees pay would still be deducted from the market price to reflect that these premiums are out of pocket costs and reduce the value of the government-provided benefit relative to a situation where no out of pocket premiums are required.

\footnotetext{
${ }^{8}$ To the extent that Medicare and Medicaid have lower levels of cost sharing, this price can be calculated as the sum of the policy with the most similar coverage in the exchange plus the expected difference in beneficiary cost-sharing in the exchange policy from that of Medicaid/Medicare. Cost-sharing can be estimated using the posted actuarial value of exchange plans. For example, a Silver Plan with a 70\% actuarial value covers $70 \%$ of the health spending of the average cost person in the risk-pool. Thus, the average beneficiary would pay $30 \%$ of their health costs. This measure does not account for any additional differences between private and public insurance with respect to provider network breadth and payment rates which may affect access to physicians and hospitals.
} 
In order to determine the magnitude of this change on the estimated value of health insurance resources for those with and without disabilities, we consider how the median resource value of those with and without disabilities would have differed in 2012 were there an option to buy insurance on the private market through the exchange without separate risk-pools. In doing so, we value Medicaid at the full unsubsidized silver premium in the exchange plus a cost sharing subsidy such that the actuarial value covers approximately 94 percent of health care costs which is similar to that currently received by Medicaid recipients. We value Medicare at the full unsubsidized premium in the exchange and add a lower cost sharing subsidy such that the actuarial value covers approximately 87 percent of health care costs, which is similar to that currently received by Medicare recipients. Those who are dually eligible are treated similarly to those on Medicaid - which has the more cost sharing subsidy of the programs. Treating the dually eligible and those on Medicaid identically reflects the prohibition on separate risk pools based on health status under the new laws, so the greater health risks that previously justified their higher market valuation no longer apply.

Table 2 shows the number of people with work limitations who, in 2012, were in each of these three categories of government provided health insurance in column 1. In column 2 it shows the median value of that coverage prior to the ACA, when there were no restrictions on rating insurance policies based on health status and pre-existing conditions. Assuming no change in this population, column 3 then shows the median value in each category, assuming that these individuals with work limitations were able to purchase policies on the exchange without rating for their pre-existing conditions. When doing so, the estimated value of government provided 
health insurance falls for those with disabilities - from over $\$ 9,000$ for each of the three ratings groups at the median to $\$ 3,200$ to $\$ 3,500$ at the median. ${ }^{9}$ This substantial reduction in the value of government provided insurance for these individuals reflects the change in the market price of insurance for these individuals based on their access to these broader risk pools.

Hence, the lower resource value of Medicare and Medicaid, combined with new subsidies $=$

for insurance policies purchased through the health insurance exchange, could incentivize individuals with disabilities to enter the labor market and earn income - even if doing so potentially limits their access to these benefits. ${ }^{10}$ Of course, to the extent that they make choices that result in leaving the Medicare or Medicaid rolls to take-up this new insurance option, it does not eliminate their health care needs but instead directly shifts part of the burden of providing these more costly health services onto policies offered through the ACA exchanges.

Changing how we estimate the market price of health insurance to reflect the post-ACA realities of the health insurance market also shifts the measured mix of in-kind and in-cash transfers for people with disabilities. Currently, a substantial and growing fraction of the household resources of working-age people with disabilities is in the form of Medicare and Medicaid. But the availability of alternate health insurance options for those who qualify to buy insurance through a health insurance exchange would reduce the desirability of Medicare and Medicaid relative to in-cash or other in-kind government transfers because the market price of

\footnotetext{
${ }^{9}$ Note that this likely represents the lower-bound of the true value of the health insurance benefits at the median, since were all individuals on Medicaid and Medicare to enter the exchanges it would likely increase the cost of premiums on the exchange.

${ }^{10}$ Changing the valuation also reduces the observed resources of those with disabilities by a similar amount. However, we emphasize that this should not be interpreted as making them worse off, but rather that it reflects the diminished importance of receiving these benefits when new outside options arise at a lower price.
} 
this equivalent health insurance is lower. However, it is important to recognize that this may not indicate that the government's cost of providing Medicare and Medicaid to these individuals has declined - but rather that the budgetary cost and the price that the recipient would pay for equivalent insurance in the market may be less aligned as additional outside health insurance options become available.

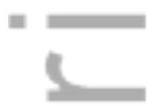

\section{CONCLUSION}

Since 2012 the Congressional Budget Office has included an estimate of the market value of government-provided health insurance coverage in its measures of household income. In this paper, we consider how the inclusion of health insurance, and other in-kind benefits impact the observed relative resources of those with and without disabilities. In doing so, we show that because the resources of those with disabilities have increasingly come in the form of health insurance, narrower cash or market-based resource measures provide a more negative assessment of the trend in their resources than is seen when using the most common approach for capturing resources more broadly. Considering resources in this broader way can help policymakers evaluate the mix of in-kind and in-cash transfers government provides, the behavioral consequences of various programs targeting those with disabilities, and the path forward for benefit programs including disability programs.

However, we also argue that the market value approach of doing so using risk-pools based on one's health status used here for income years 1980-2012, will beginning in income year 2014 no longer be appropriate in light of the prohibition against rating on pre-existing conditions in the Affordable Care Act. Continuing to estimate the resource value of health 
insurance based on the market value of risk-pools that are no longer permitted in the private market after that date will overstate the value of these benefits to the Medicare and Medicaid recipients. Using our proposed approach for estimating market value based on the cost of equivalent policies in the health insurance exchanges, we conclude that Medicare and Medicaid would have a lower resource value for those who continue on these programs beginning in 2014 . Recognizing that the cost to purchase an equivalent policy is a key aspect of economic decisions for beneficiaries of these programs, this new approach will allow for more accurate assessments of how beneficiaries will react both to economic opportunities and to potential policy changes.

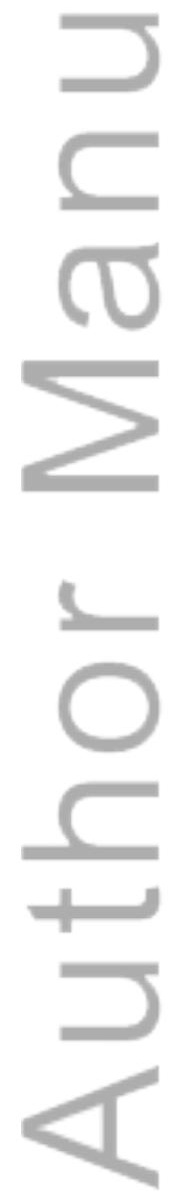




\section{REFERENCES}

Aaron, H., and G. Burtless. "Potential Effects of the Affordable Care Act on Income Inequality" Brookings Institution Working Paper, 2014.

Armour, P., R.V. Burkhauser, and J. Larrimore. "Levels and Trends in United States Income and Its Distribution: A Crosswalk from Market Income towards a Comprehensive HaigSimons Income Measure.” Southern Economic Journal 81(2), 2014, 271-93.

Atkinson, A.B., and A. Brandolini. "Promises and Pitfalls in the Use of Secondary Data Sets: Income Inequality in OECD Countries as a Case Study." Journal of Economic Literature 39(3), 2001, 771-99.

Atkinson, A.B., T. Piketty, and E. Saez. “Top Incomes in the Long Run of History.” Journal of Economic Literature 49(1), 2011, 3-71.

Benítez-Silva, H., M. Buchinsky, H.M. Chan, S. Sheidvasser, and J. Rust. 2004. "How Large Is the Bias in Self-Reported Disability?" Journal of Applied Econometrics 19(6), 2004, 64970 .

Blank, R.M. Changing Inequality. Berkeley, CA: University of California Press, 2011.

Bound, J., and R.V. Burkhauser. "Economic Analysis of Transfer Programs Targeted on People with Disabilities," in Handbook of Labor Economics, Vol. 3C, edited by O. Ashenfelter and D. Card. Amsterdam: Elsevier Science North-Holland, 1999, 3417-528.

Burkhauser, R.V., M.C. Daly, A.J. Houtenville, and N. Nargis. 2002. "Self-Reported WorkLimitation Data: What They Can and Cannot Tell Us.” Demography 39(3), 2002, 54155.

Burkhauser, R.V., and M.C. Daly. The Declining Work and Welfare of People with Disabilities: What Went Wrong and a Strategy for Change. Washington, DC: The AEI Press, 2011.

Burkhauser, R.V., T.L. Fisher, A.J. Houtenville, and J. Tennant. "Is the 2010 Affordable Care - Act Minimum Standard to Identify Disability in All National Datasets Good Enough for -Policy Purposes?” Journal of Economic and Social Measurement. 39 (2), 2015, 217-245.

Burkhauser, R.V., A.J. Houtenville, and J. Tennant. "Capturing the Elusive Working-Age Population with Disabilities: Reconciling Conflicting Social Success Estimates from the Current Population Survey and American Community Survey." Journal of Disability Policy Studies 24(4), 2014, 195-205. 
Burkhauser, R.V. and J. Larrimore. "Using Internal CPS Data to Reevaluate Trends in LaborEarnings Gaps.” Monthly Labor Review, August 2009, 3-18.

Burkhauser, R.V., J. Larrimore and K. Simon. "A Second Opinion on the Economic Health of the American Middle Class and Why it Matters in Gauging the Impact of Government Policy." National Tax Journal 65(1), 2012, 7-32.

Burkhauser, R.V., J. Larrimore, and K. Simon. "Measuring the Impact of Valuing Health Insurance on Levels and Trends in Inequality and how the Affordable Care Act of 2010 = Could Affect Them." Contemporary Economic Policy 31(4), 2013, 779-94.

Burtless, G., and S. Milusheva. "Effects of Employer-Sponsored Health Insurance Costs on Social Security Taxable Wages," Social Security Bulletin 73(1), 2013, 83-108.

Burtless, G., and P. Svaton. "Health Care, Health Insurance, and the Distribution of American Incomes," Forum for Health Economics \& Policy 13(1), 2010.

Census Bureau. "Estimates of Poverty Including the value of Noncash Benefits: 1987." (August) Washington DC: U.S. Government Printing Office, 1988.

Census Bureau. "Measuring the Effect of Benefits and Taxes on Income and Poverty: 1992" Current Population Reports P60-186RD, 1993

Congressional Budget Office (CBO). "The Distribution of Household Income between 1979 and 2007.” Washington DC: U.S. Government Printing Office, 2011.

Congressional Budget Office (CBO). "The Distribution of Income and Federal Taxes, 2008 and 2009.” Washington, DC: U.S. Government Printing Office, 2012.

Congressional Budget Office (CBO). "The Distribution of Income and Federal Taxes, 2010." Washington, DC: U.S. Government Printing Office, 2013.

Daly, M.C., and R.G. Valletta. "Inequality and Poverty in the United States: The Effects of Rising Dispersion of Men's Earnings and Changing Family Behavior." Economica 73(289), 2006, 75-98.

Davern, M., J.A. Klerman, D.K. Baugh, K.T. Call, and G.D. Greenberg. "An Examination of the Medicaid Undercount in the Current Population Survey: Preliminary Results from Record Linking” Health Services Research 44(3), 2009, 965-987.

DeNavas Walt, C., and B.D. Proctor. U.S. Census Bureau, Current Population Reports P60-249, Income and Poverty in the United States: 2013. Washington, DC: U.S. Government Printing Office, 2014. 
d'Ercole, M.M., and M. Förster. "The OECD Approach to Measuring Income Distribution and Poverty: Strengths, Limits and Statistical Issues," In European Measures of Income and Poverty: Lessons for the U.S., edited by D.J. Besharov and K.A. Couch. New York, NY: Oxford University Press, 2012.

Feenberg, D., and E. Coutts. “An Introduction to the TAXSIM Model.” Journal of Policy Analysis and Management 12(1), 1993, 189-94.

Finkelstein, Amy, Nathaniel Hendren, and Erzo F.P. Luttmer. 2015. "The Value of Medicaid: = Interpreting Results from the Oregon Health Insurance Experiment," NBER Working Paper 21308.

Garthwaite, Craig, Tal Gross, and Matthew J. Notowidigdo. 2015. "Hospitals as Insurers of Last Resort,” NBER Working Paper 21290.

Gottschalk, P., and S. Danziger. "Inequality of Wage Rates, Earnings and Family Income in the United States, 1975-2002." Review of Income and Wealth 51(2), 2005, 231-54.

Gottschalk, P., and T.M. Smeeding. 1997. "Cross-National Comparisons of Earnings and Income Inequality." Journal of Economic Literature 35(2), 1997, 633-87.

Houtenville, A.J., D.C. Stapleton, R.R. Weathers II, and R.V. Burkhauser (eds.) Counting Working-age People with Disabilities: What Current Data Tell Us and Options for Improvement. Kalamazoo, MI: W.E. Upjohn Institute for Employment Research, 2009.

Interagency Technical Working Group. "Observations from the Interagency Technical Working Group on Developing a Supplemental Poverty Measure," 2010. Available at: http://www.census.gov/hhes/www/poverty/SPM_TWGObservations.pdf

Larrimore, J., R.V. Burkhauser, S. Feng, and L. Zayatz. "Consistent Cell Means for Topcoded Incomes in the Public Use March CPS (1976-2007)." Journal of Economic and Social Measurement 33(2-3), 2008, 89-128.

Livermore, G., D.C. Stapleton, and M. O'Toole. "Health Care Costs are a Key Driver of Growth in Federal and State Assistance to Working-Age People with Disabilities." Health Affairs 30(9), 2011, 1664-72.

MaCurdy, T. "How Effective is the Minimum Wage at Supporting the Poor?" Journal of Political Economy 123(2), 2015, 497-545.

Nunns, J., A. Eng, and L. Austin. "Description and Analysis of the Camp Tax Reform Plan" Urban-Brookings Tax Policy Center Research Report, 2014. 
Pascale, J., M. Roemer, and D.M. Resnick. "Medicaid Underreporting in the CPS: Results from a Record Check Study" U.S. Census Bureau Research Report on Survey Methodology \#2007-40, 2007.

Pascale, J., M. Boudreaux, and R. King. "Understanding the New Current Population Survey Health Insurance Questions" Health Services Research 51(1), 2016, 240-261.

Piketty, T., and E. Saez. "Income Inequality in the United States, 1913-1998." Quarterly Journal of Economics 118(1), 2003, 1-39.

Ruggles, P. Drawing the Line: Alternative Poverty Measures and their Implication for Public Policy. Washington, DC: Urban Institute Press, 1990.

Sommers, B.D., and D. Oellerich. "The Poverty Reducing Effect of Medicaid." Journal of Health Economics 32(5), 2013, 816-32.

Stapleton, D.C. "Bending the Employment, Income, and Cost Curves for People with "Disabilities," Center for Studying Disability Policy, Washington DC, 2011.

Stern, S. "Measuring the Effect of Disability on Labor Force Participation," Journal of Human Resources 24(3), 1989, 361-95.

Stewart, K.J., and S.B. Reed. “CPI Research Series Using Current Methods, 1978-98.” Monthly Labor Review 122(6), 1999, 29-38.

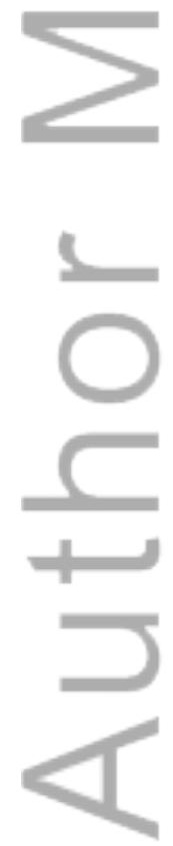


Figure 1. Yearly value of publically provided health insurance and disability-based cash transfers and the share of health insurance in that total for working-age people with disabilities (1980-2012)

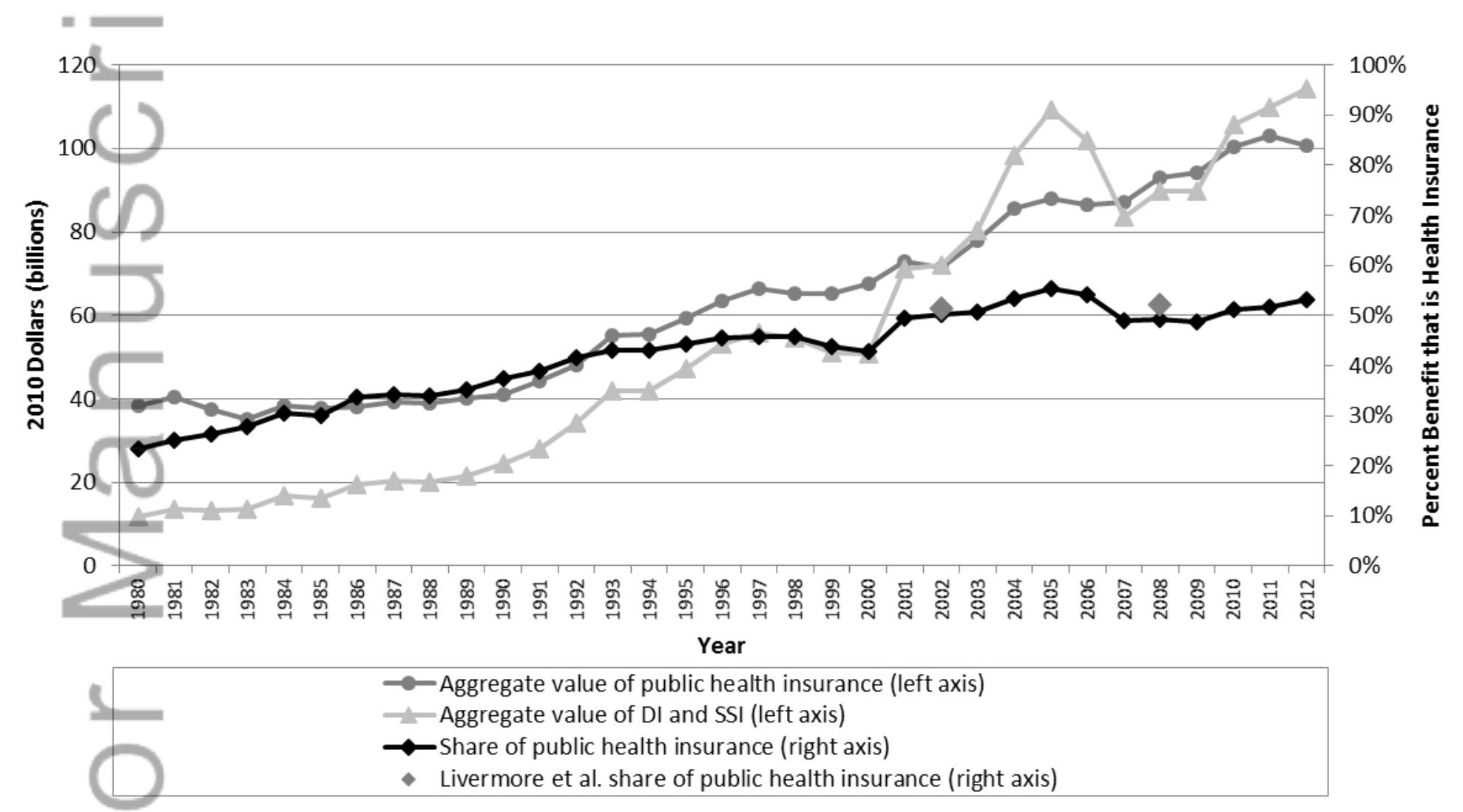

Source: Author's calculation from March CPS data and Livermore et al. (2011)

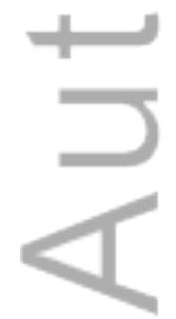


Notes: Publically provided health insurance (Public HI) includes the market value of Medicare and Medicaid; disability-based cash transfers include DI and SSI benefits (DI and SSI) based on CPS reported data for working-age people with disabilities; Livermore et al. (2011, unpublished Data Appendix Exhibits 1A and 2A) values estimate these benefits based on aggregate program data. All dollar values are adjusted to 2010 dollars using the CPI-U-RS. See the technical appendix for additional details on series construction.

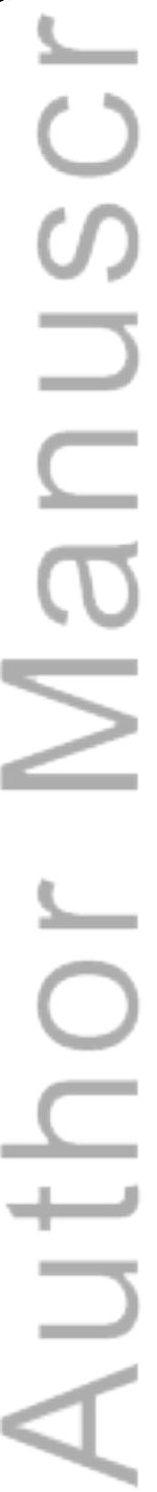

This article is protected by copyright. All rights reserved. 
Figure 2. Trends in public and private health insurance coverage and disability-based cash transfers and their value for working-age people with disabilities (1980-2012)
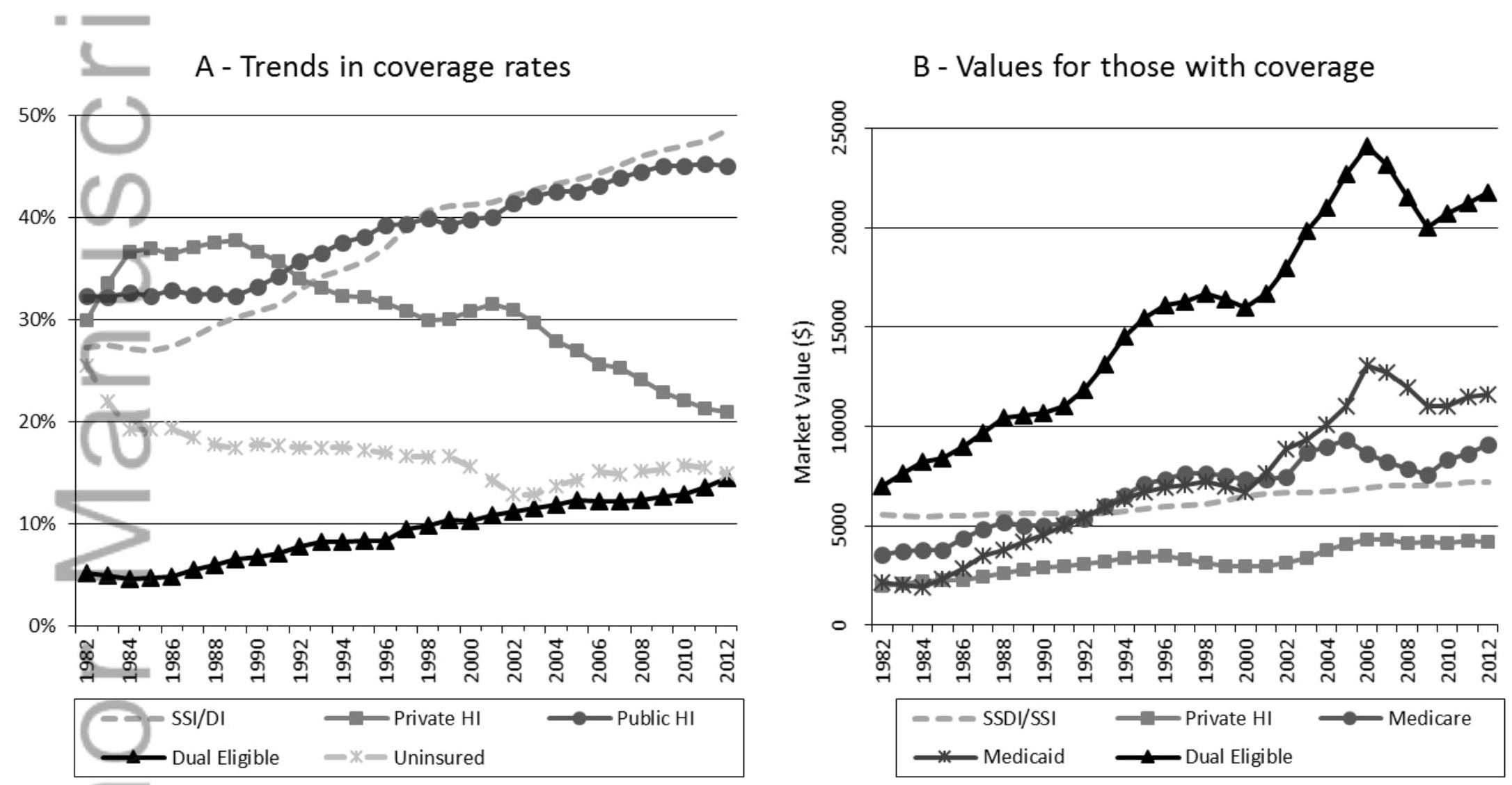

Source: Author's calculation from March CPS data.

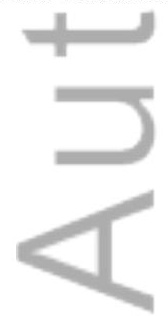


Notes: Yearly values are three-year moving averages with 1982 being the mean value of 1980-1982. Prevalence rates of working-age (18-64) people with disabilities covered by Medicare or Medicaid (Public HI), Medicare and Medicaid (Dual Eligible), and employer-provided health insurance (Private HI), those not covered by these sources of health insurance (Uninsured), and those receiving Social Security Disability Insurance or Supplemental Security Income (DI/SSI) benefits. All dollar values are adjusted to 2010 dollars using the CPI-U-RS. See Appendix Figure $1 \mathrm{~A}$ for equivalent figures for the population of working-age people without disabilities.

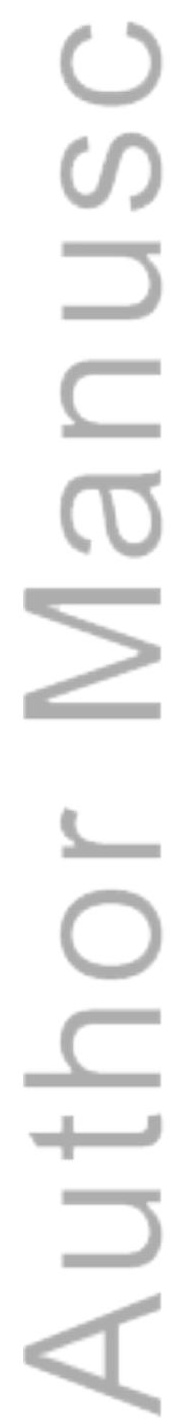

This article is protected by copyright. All rights reserved. 
Figure 3. Trends in median size-adjusted income by income definition for working-age people with and without disabilities (1980-2012)
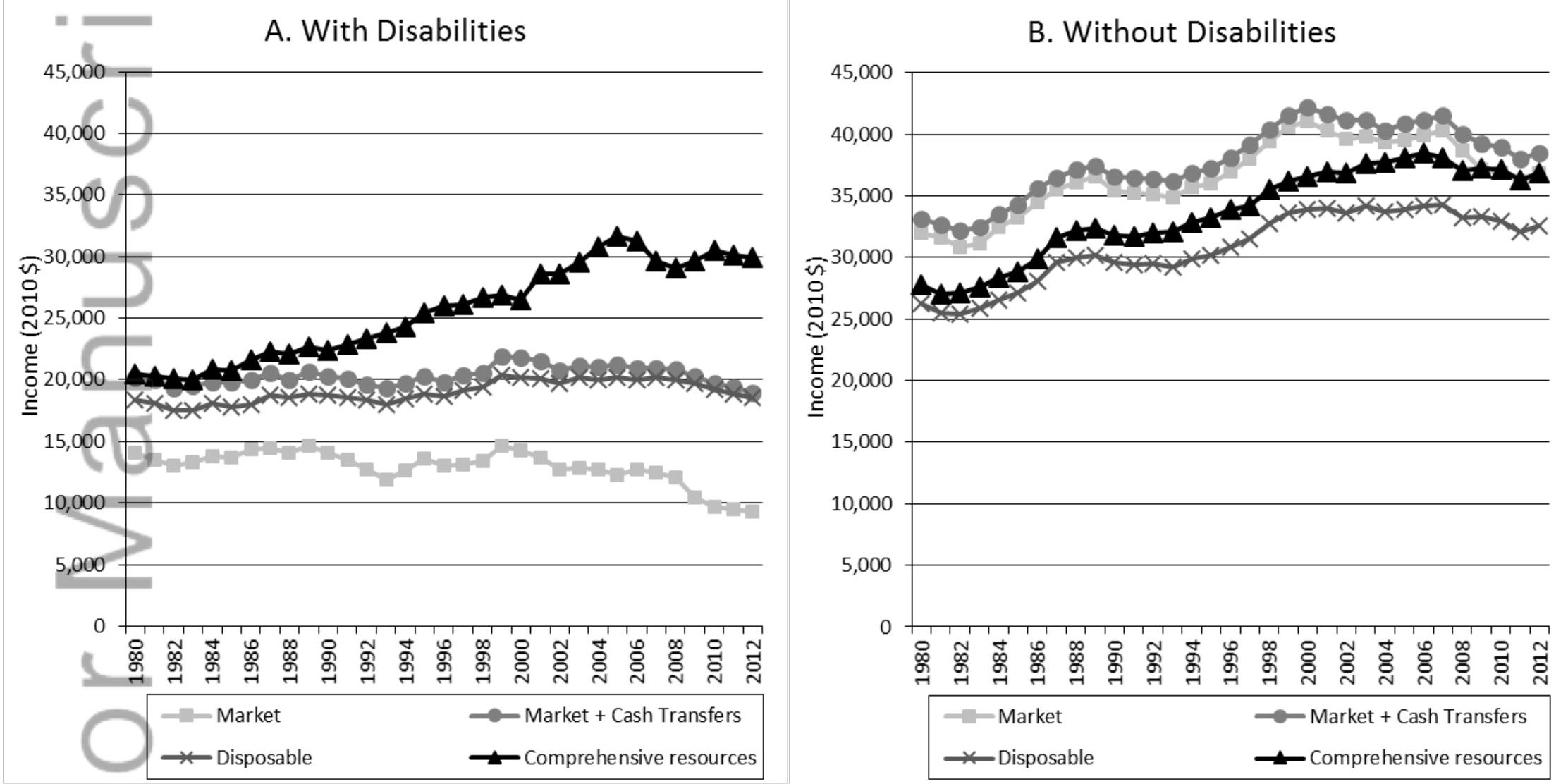

Source: Author's calculation from March CPS data.

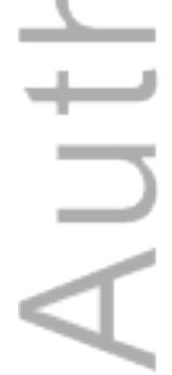


Notes: Median household size-adjusted income in 2010 dollars of working-age (18-64) people with and without disabilities by resource definition (1980-2012). All dollar values are adjusted to 2010 dollars using the CPI-U-RS. See the technical appendix for additional details on the components of income in each series.

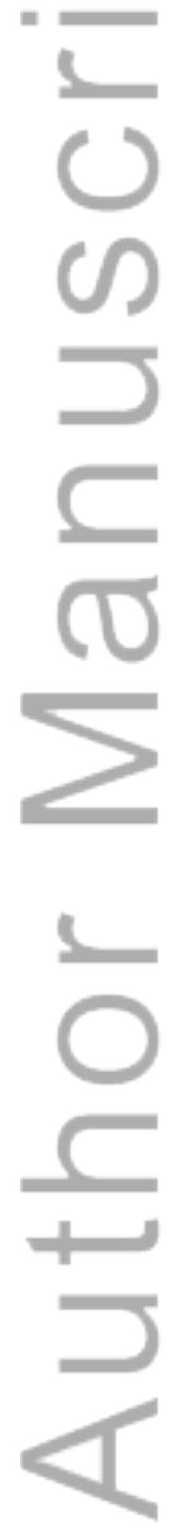




\section{Figure 4. Trends in the Disability Median Resource Gap by Resource Definition}

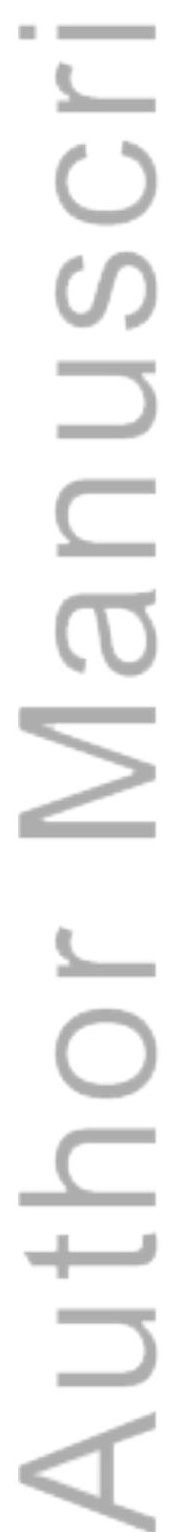




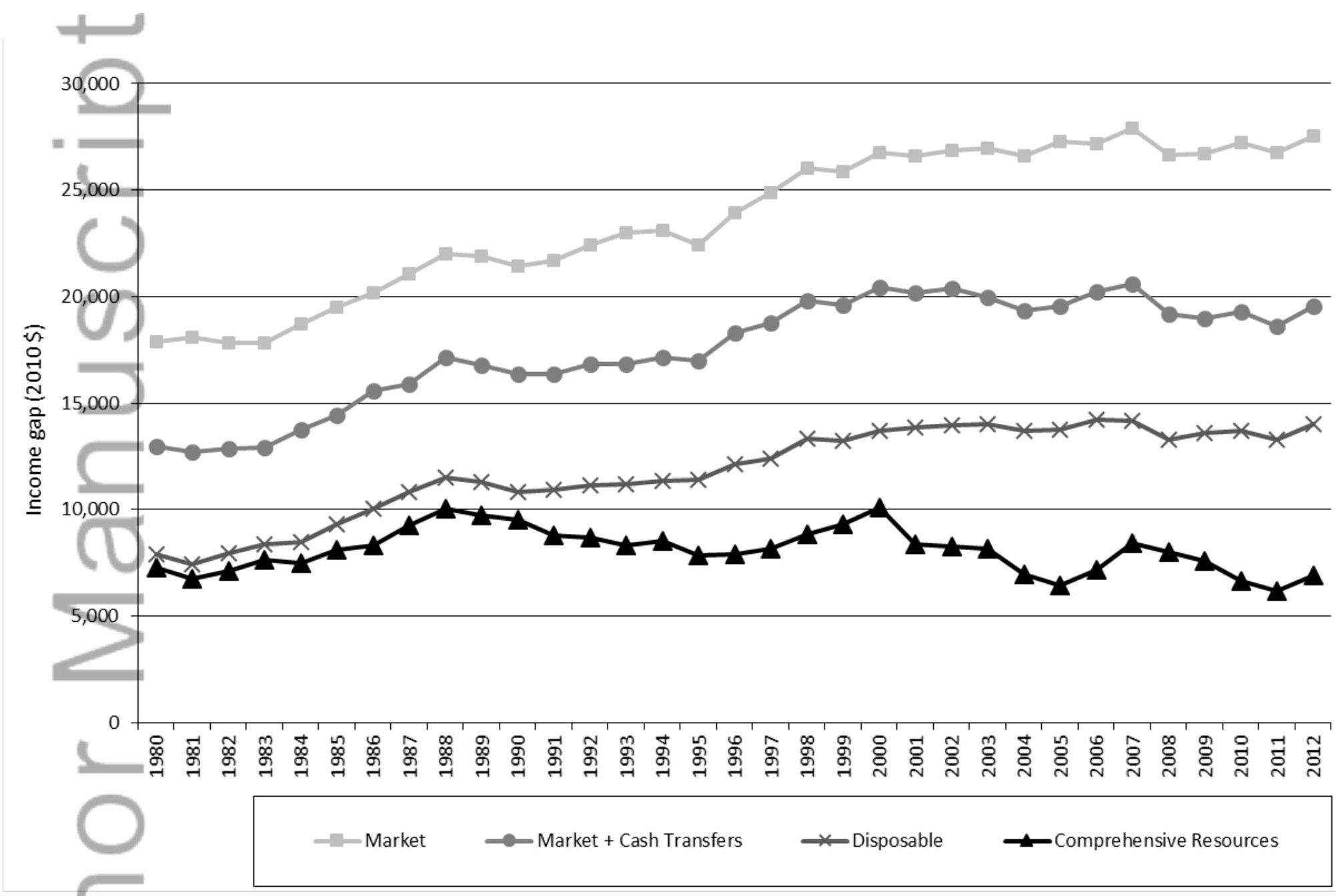

Source: Author's calculation from March CPS data.

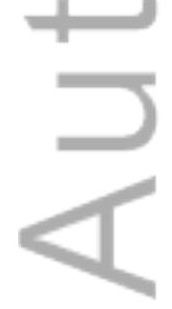

This article is protected by copyright. All rights reserved. 
Notes: Gap between the median size-adjusted income of working-age (18-64) people without and with disabilities based on values for relevant income measures in 2010 dollars in Figure 3 (1980- 2012). All dollar values are adjusted to 2010 dollars using the CPI-U-RS.

Figüre 5. Share of All Working Aged Persons who have Disabilities in Trough Year Size-adjusted Resource Quintiles, based on Comprehensive Resources plus the Value of Health Insurance 


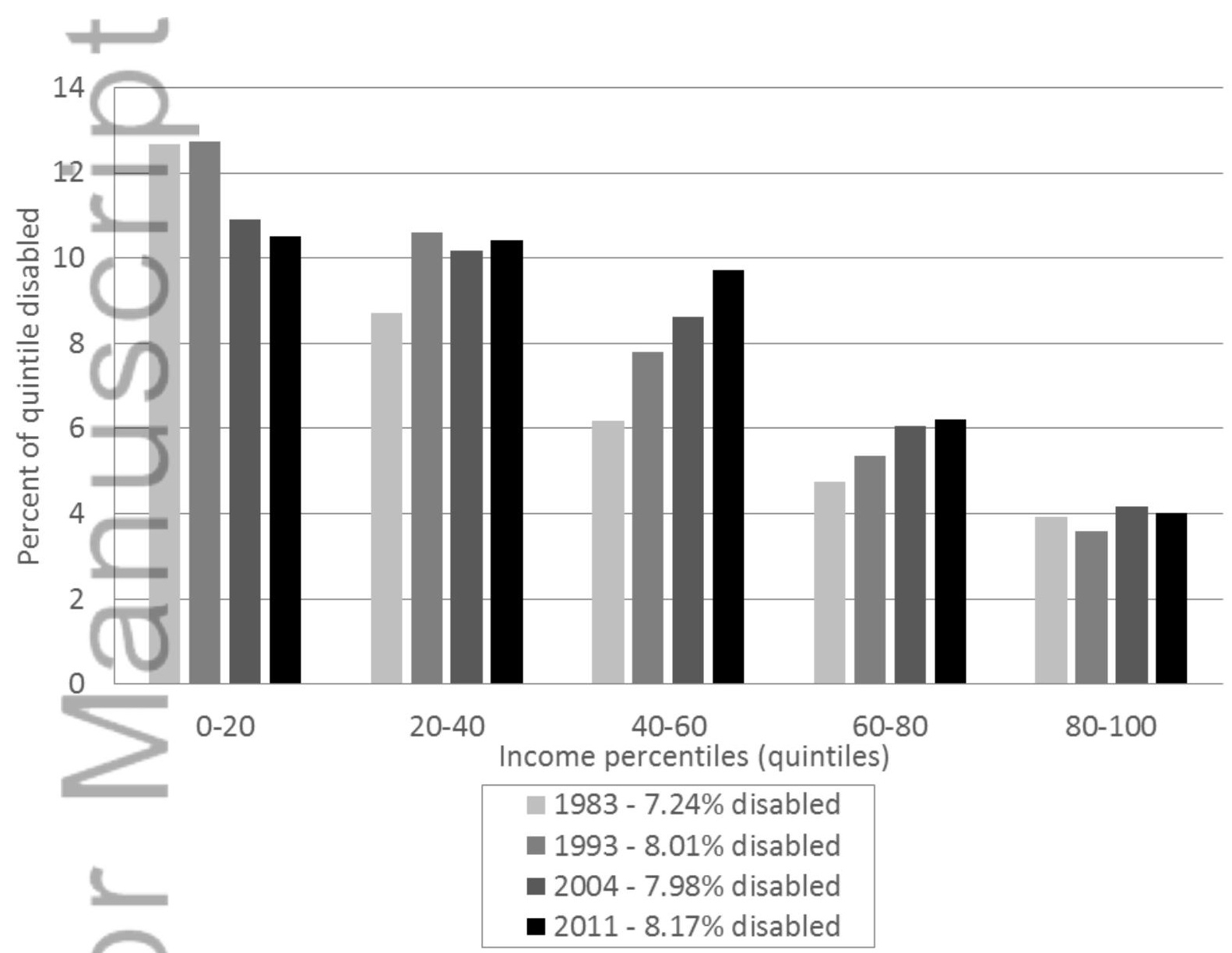

Source: Author's calculation from March CPS data.

Notes: The legend above shows by trough year the percent of all working age persons who report a work limitation in that year.

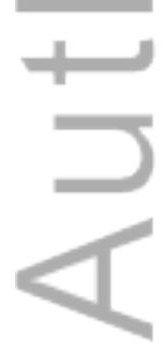

This article is protected by copyright. All rights reserved. 
Table 1. Trends in the share of gross mean resources including the value of health insurance by income source for working-age people with and without disabilities

\begin{tabular}{|c|c|c|c|c|c|c|c|c|c|c|c|c|}
\hline Year & $\begin{array}{l}\text { Mean } \\
\text { Gross } \\
\text { (pre-tax) } \\
\text { Size- } \\
\text { adjusted } \\
\text { Resources } \\
(2010 \$)\end{array}$ & $\begin{array}{c}\text { Own } \\
\text { Labor } \\
\text { Income } \\
\end{array}$ & $\begin{array}{l}\text { Others' } \\
\text { Labor } \\
\text { Income } \\
\end{array}$ & $\begin{array}{l}\text { Private } \\
\text { Non- } \\
\text { Labor } \\
\text { Income } \\
\end{array}$ & $\begin{array}{c}\text { DI/SSI } \\
\text { Cash } \\
\text { Transfers } \\
\end{array}$ & $\begin{array}{c}\text { Other } \\
\text { Public } \\
\text { Cash } \\
\text { Transfers } \\
\end{array}$ & $\begin{array}{c}\text { Public in- } \\
\text { kind } \\
\text { transfers } \\
\text { excluding } \\
\text { HI } \\
\end{array}$ & $\begin{array}{c}\text { Private } \\
\text { Health } \\
\text { Insurance }\end{array}$ & $\begin{array}{l}\text { Public } \\
\text { Health } \\
\text { Insurance to } \\
\text { DI/SSI } \\
\text { recipients }\end{array}$ & $\begin{array}{c}\text { Other } \\
\text { Public } \\
\text { Health } \\
\text { Insurance }\end{array}$ & $\begin{array}{l}\text { Total } \\
\text { Share } \\
\end{array}$ & Taxes \\
\hline & \multicolumn{12}{|c|}{ With Disabilities } \\
\hline 1983 & 27,487 & 17.45 & 37.52 & 15.83 & 13.21 & 6.07 & 1.1 & 2.64 & 4.89 & 1.29 & 100.00 & 15.46 \\
\hline 1993 & 31,104 & 15.43 & 34.54 & 12.46 & 14.67 & 5.21 & 1.29 & 3.16 & 10.72 & 2.51 & 100.00 & 11.92 \\
\hline 2004 & 38,588 & 11.75 & 32.66 & 11.61 & 15.43 & 3.62 & 0.81 & 3.21 & 17.18 & 3.72 & 100.00 & 10.13 \\
\hline 2011 & 37,101 & 8.23 & 32.20 & 10.87 & 18.00 & 3.70 & 1.47 & 2.78 & 18.43 & 4.32 & 100.00 & 8.99 \\
\hline \multicolumn{13}{|c|}{ Without Disabilities } \\
\hline 1983 & 9,213 & 40.12 & 43.80 & 7.52 & 1.98 & 1.73 & 0.34 & 3.65 & 0.49 & 0.38 & 100.00 & 23.65 \\
\hline 1993 & 47,613 & 40.76 & 42.16 & 7.54 & 1.80 & 1.30 & 0.32 & 4.68 & 0.83 & 0.60 & 100.00 & 22.25 \\
\hline 2004 & 55,181 & 41.62 & 41.35 & 6.85 & 1.75 & 0.69 & 0.20 & 5.41 & 1.28 & 0.85 & 100.00 & 20.34 \\
\hline 2011 & 53,478 & 40.49 & 41.46 & 6.29 & 2.19 & 1.19 & 0.39 & 5.05 & 1.58 & 1.37 & 100.00 & 19.36 \\
\hline
\end{tabular}

Source: Author's calculation from March CPS data.

Notes: Column 1 reports yearly mean before tax gross resources including the market value of private and publically provided health insurance. This is income definition 4 but net of taxes in 2010 dollars for working-age (18-64) persons with and without disabilities for trough years. The next nine columns report the percentage of gross resources accounted for by that source of income each year. These values sum to 100 in each year. The last column reports the decline in the share of gross resources in each year caused by taxes. All dollar values are adjusted to 2010 dollars using the CPI-U-RS.

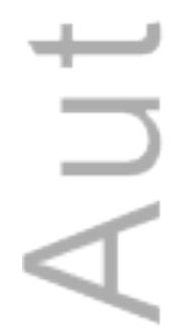


Table 2. Comparison of the Median Estimated Value of Government Provided Health Insurance Policies Under the Pre- and Post-ACA Risk-Pools

\begin{tabular}{lrrr}
\hline & $\begin{array}{r}\text { Number } \\
\text { Of people with } \\
\text { work limitations }\end{array}$ & $\begin{array}{r}\text { Median value with } \\
\text { rating for pre-existing } \\
\text { conditions (Pre-ACA) } \\
(2010 \$)\end{array}$ & $\begin{array}{r}\text { Median value without } \\
\text { rating for pre-existing } \\
\text { conditions (Post-ACA) }\end{array}$ \\
\hline Medicare & $3,085,841$ & 9,459 & 3,232 \\
Medicaid & $4,013,270$ & 10,770 & 3,470 \\
Dual-Eligible & $2,476,503$ & 22,115 & 3,470 \\
\hline
\end{tabular}

Source: Author's calculation from March CPS data.

Notes: All dollar values are adjusted to 2010 dollars using the CPI-U-RS.

This article is protected by copyright. All rights reserved. 


\section{Appendix}

\section{Methods for the Text Figures}

\section{$\underline{\text { Figure } 1 \text { Methods }}$}

Values for spending on DI/SSI come from CPS income source questions. SSI income is reported as a separate income source while Social Security income includes all Social Security Administration cash program payments (e.g., Old-Age and Survivor Insurance, Disability Insurance, and Disabled Adult Child benefits). We assume that all these cash payments to people aged 18-64 who report a work activity limitation are DI cash transfers. ${ }^{11}$ Our market values for public health insurance are imputed by the Census and reflect the average cost of the Medicaid and/or Medicare program by state of residence and eligibility mechanism (e.g., New York State Medicaid-eligible through SSI enrollment). We include the market value of public health insurance only when the individual reports receiving DI/SSI cash transfers. Note that the market value of Medicare as estimated by the Census Bureau subtracts Supplemental Medical Insurance (SMI) premium payments made by Medicare beneficiaries for Part B and Part D insurance since these premium payments are assumed to be paid by the beneficiary.

Livermore et al. (2011) compile their measure of DI and SSI cash benefits and Medicare and Medicaid expenditures for working-age people with disabilities based on aggregate government expenditure data for 2002 and 2008. Our methods can only approximate their methods and vary somewhat in levels for DI/SSI and public health insurance. But as can be seen in Figure 1 our share of public health insurance values are quite similar in level and trend to their values in 2002 and 2008. More importantly, we are able to extend our analysis over a much longer period and hence put these two years in a broader perspective.

Figure 3 Methods

The sources of income obtained in the March CPS data that are subcomponents of the various income definitions in Figure 3 are:

1. Own labor income - Income from one's own labor earnings.

2. Labor income of others - Income from the labor earnings of others in the household.

3. Private non-labor income - Non-labor income of all persons in the household (e.g., rental income).

\footnotetext{
${ }^{11}$ This assumption includes OASI spending from the SSA on people aged 62 to 64 who report a work activity limitation. Limiting the sample to persons aged 18 to 61 reduces cash and health insurance payments by $19 \%$ and $13 \%$ (on average), respectively. This limitation reduced payments more between 1980 and 1989 compared to after 1990. Thus, limiting the population to people aged 18 to 61 would yield higher growth rates in DI/SSI spending on both cash transfers and health insurance over the 1980 to 2012 window than what we currently present in our main analysis.
} 
4. DI/SSI cash transfers - Cash DI/SSI transfers to all persons in the household.

5. Other public cash transfers - All other cash transfer programs (except DI/SSI) to all persons in the household (e.g., Temporary Assistance for Needy Families (TANF)).

6. Public in-kind transfers excluding the value of health insurance - Census Bureau's imputed market value of the Supplemental Nutrition Assistance Program (SNAP), school

-lunches, and housing subsidies to all persons in the household.

7. Market value of public health insurance for persons on the DI/SSI rolls - Census Bureau's imputed market value of Medicaid, Medicare, or both for persons on the DI/SSI

= rolls.

8. Market value of public health insurance for persons not on the DI/SSI rolls - Census Bureau's imputed market value of Medicaid, Medicare, or both for persons not on the DI/SSI rolls.

9. Employer contributions to employment-based health insurance plans - Census Bureau's imputed dollar contribution of employers to employment-based health insurance.

10. Taxes - National Bureau of Economic Research (NBER) TaxSim 9.0's estimated values of taxes paid by households divided by their pre-tax gross household income. See Feenberg and Coutts, 1993 for more information on the TaxSim program.

The market income series consists of items 1,2, and 3 above. The market plus cash transfers series consists if items 1 through 5 above. The disposable income series consists of items 1 through 6 above as well as item 10. Finally, the comprehensive resources plus the market value of health insurance series consists of items 1 through 10 above. 
Appendix Figure $1 A$ - Trends in public and private health insurance coverage and disability-based cash transfers and their value for working-age people without disabilities (1980-2012)
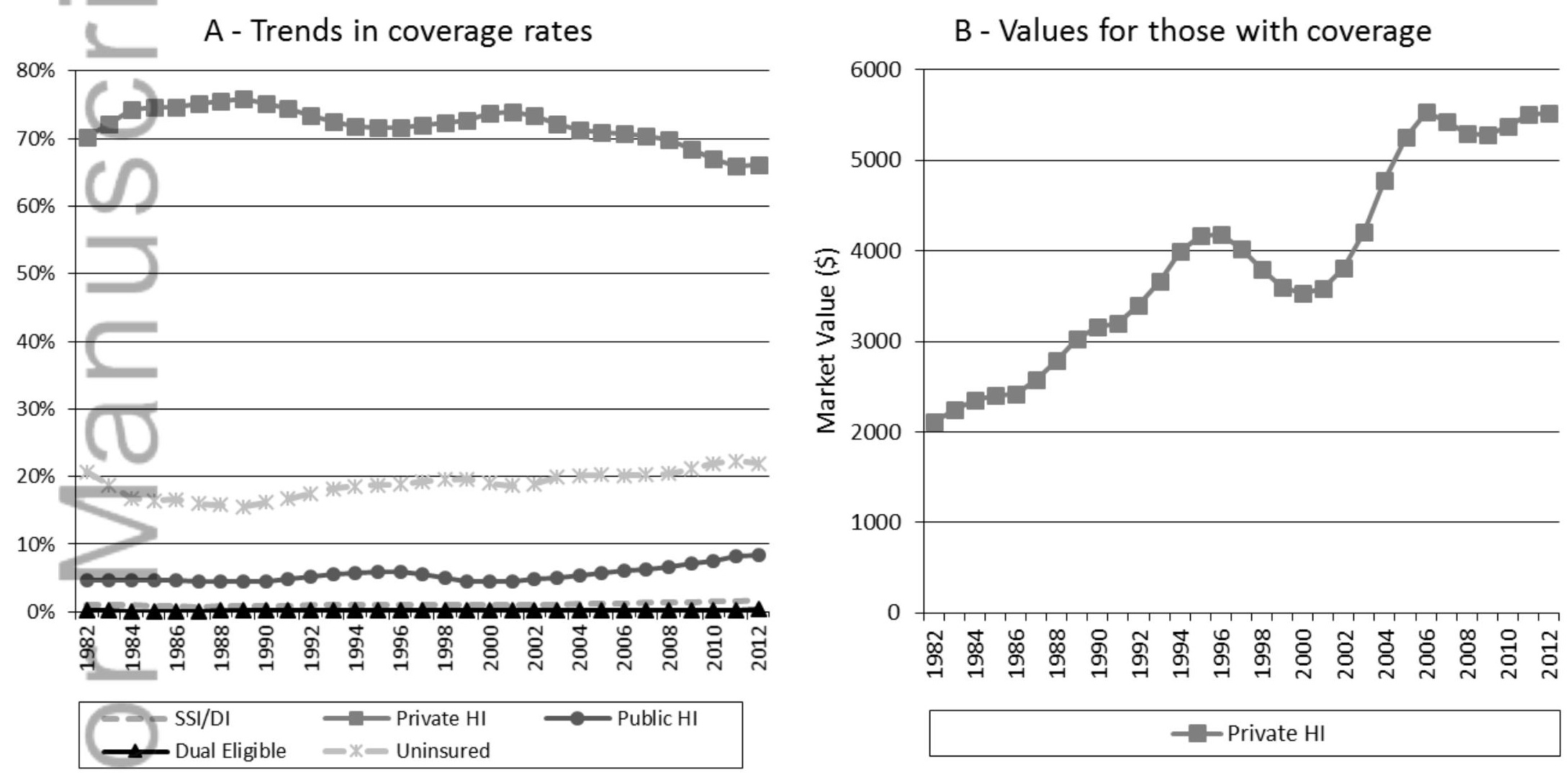

Source: Author's estimation from March CPS data.

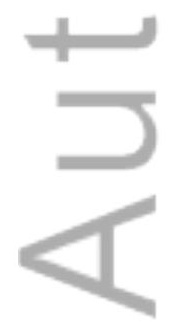

This article is protected by copyright. All rights reserved. 
Notes: Yearly values are three-year moving averages with 1982 being the mean value of 1980-1982. Prevalence rates of working-age (18-64) people with disabilities covered by Medicare or Medicaid (Public HI), Medicare and Medicaid (Dual Eligible), and employer-provided health insurance (Private HI), those not covered by these sources of health insurance (Uninsured), and those receiving Social Security Disability Insurance or Supplemental Security Income (DI/SSI) benefits. All dollar values are adjusted to 2010 dollars using the CPI-U-RS. Recognizing the limited take-up of other forms of health insurance, only the value of employer contributions to private health insurance are included.

Appendix Table 1A. Demographic Characteristics of People with and without Disabilities

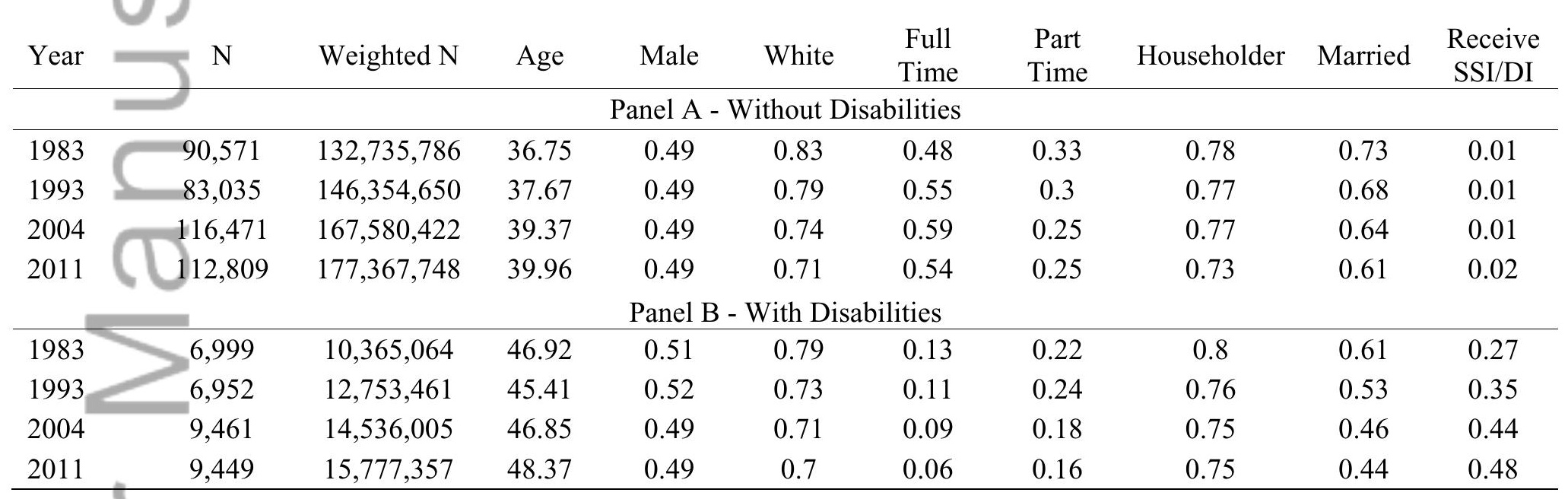

Source: Author's estimation from March CPS data.

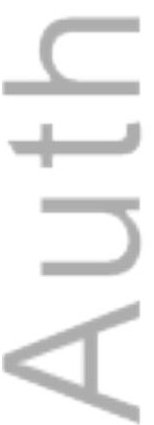




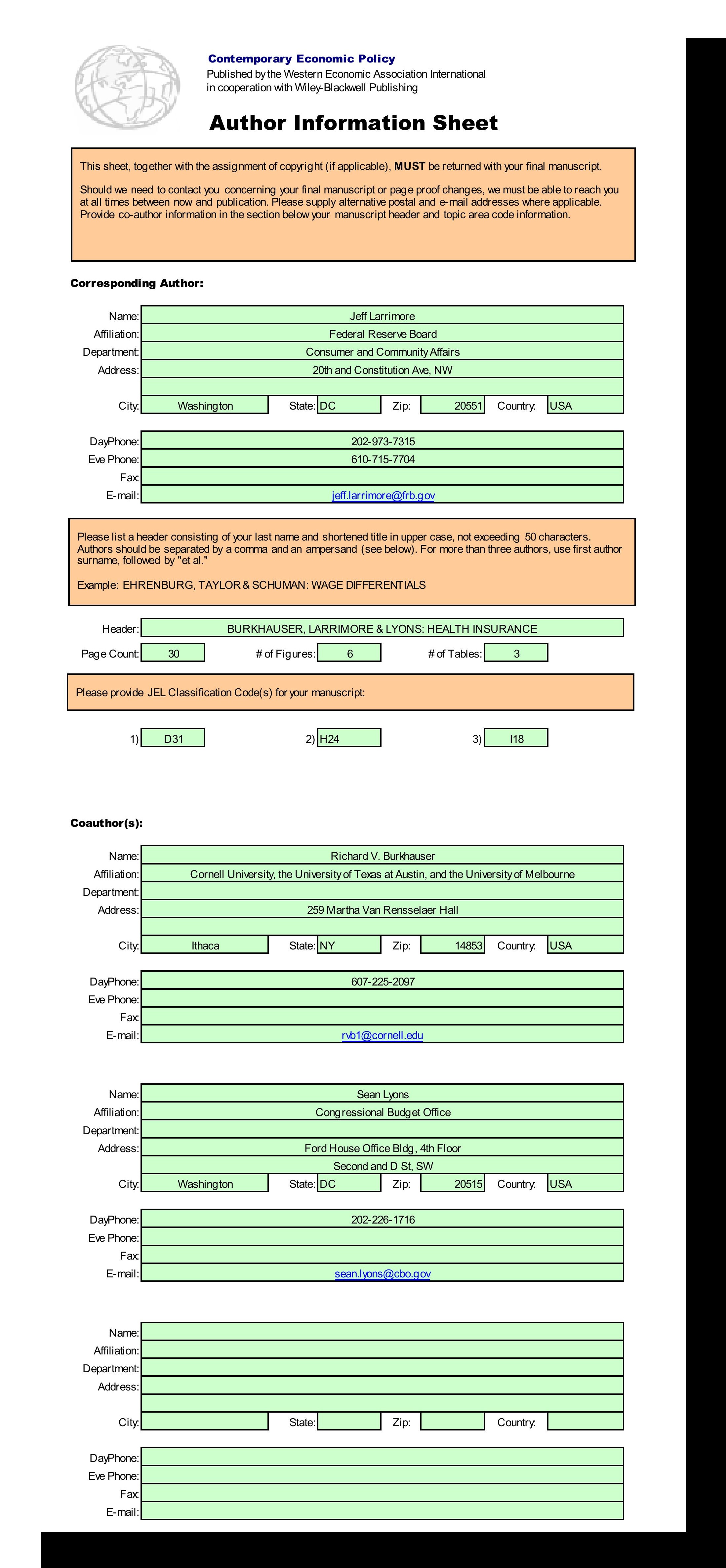

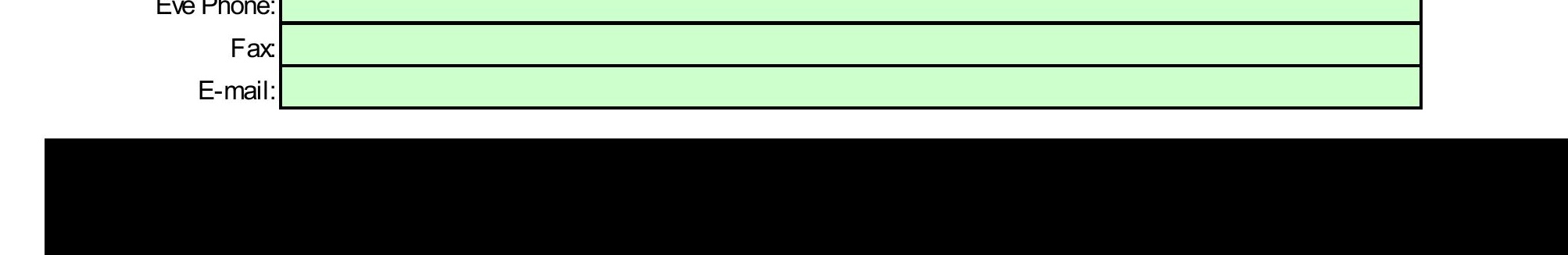




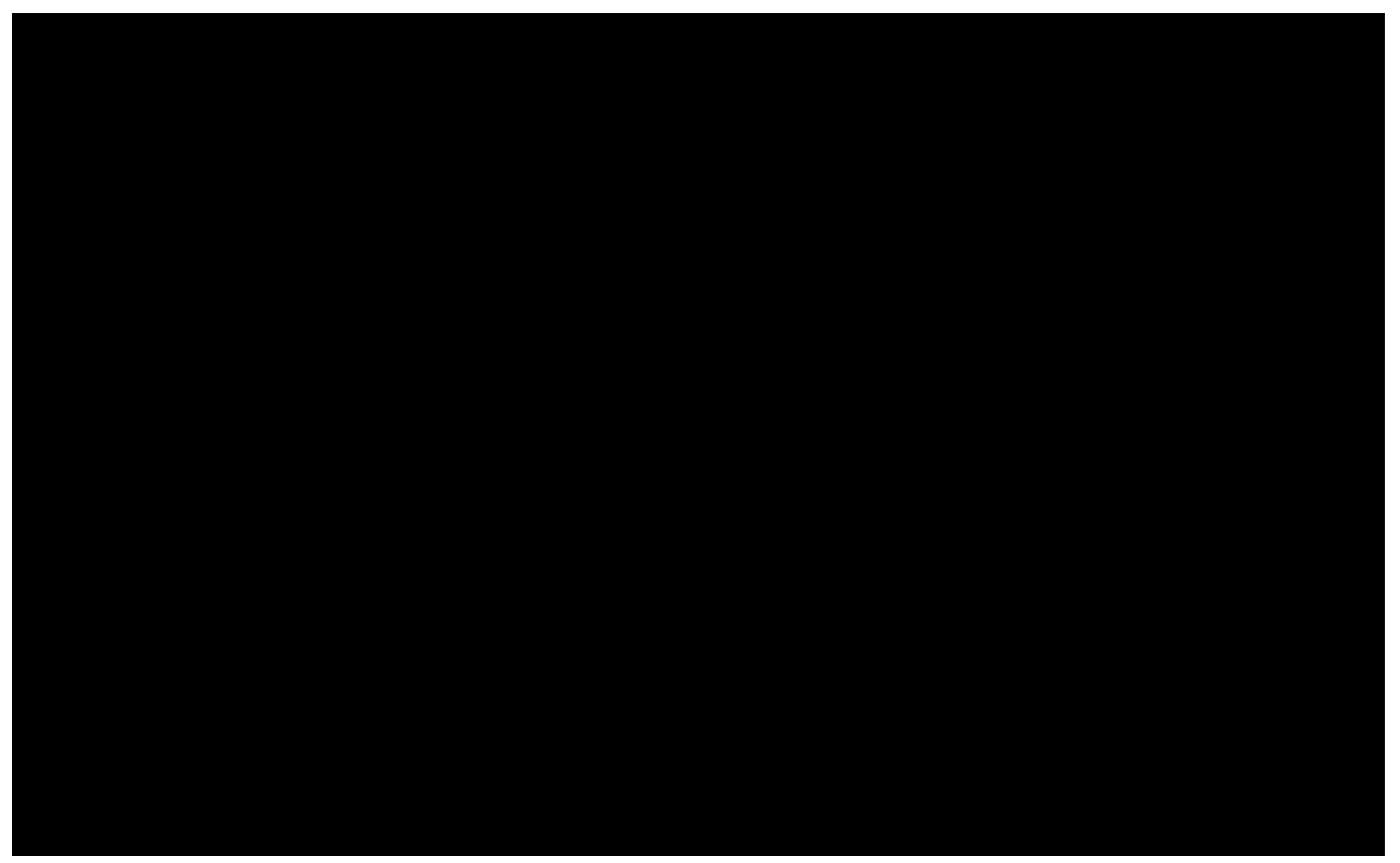


Figure 1. Yearly value of publically provided health insurance and disability-based cash transfers and the share of health insurance in that total for working-age people with disabilities (1980-2012)
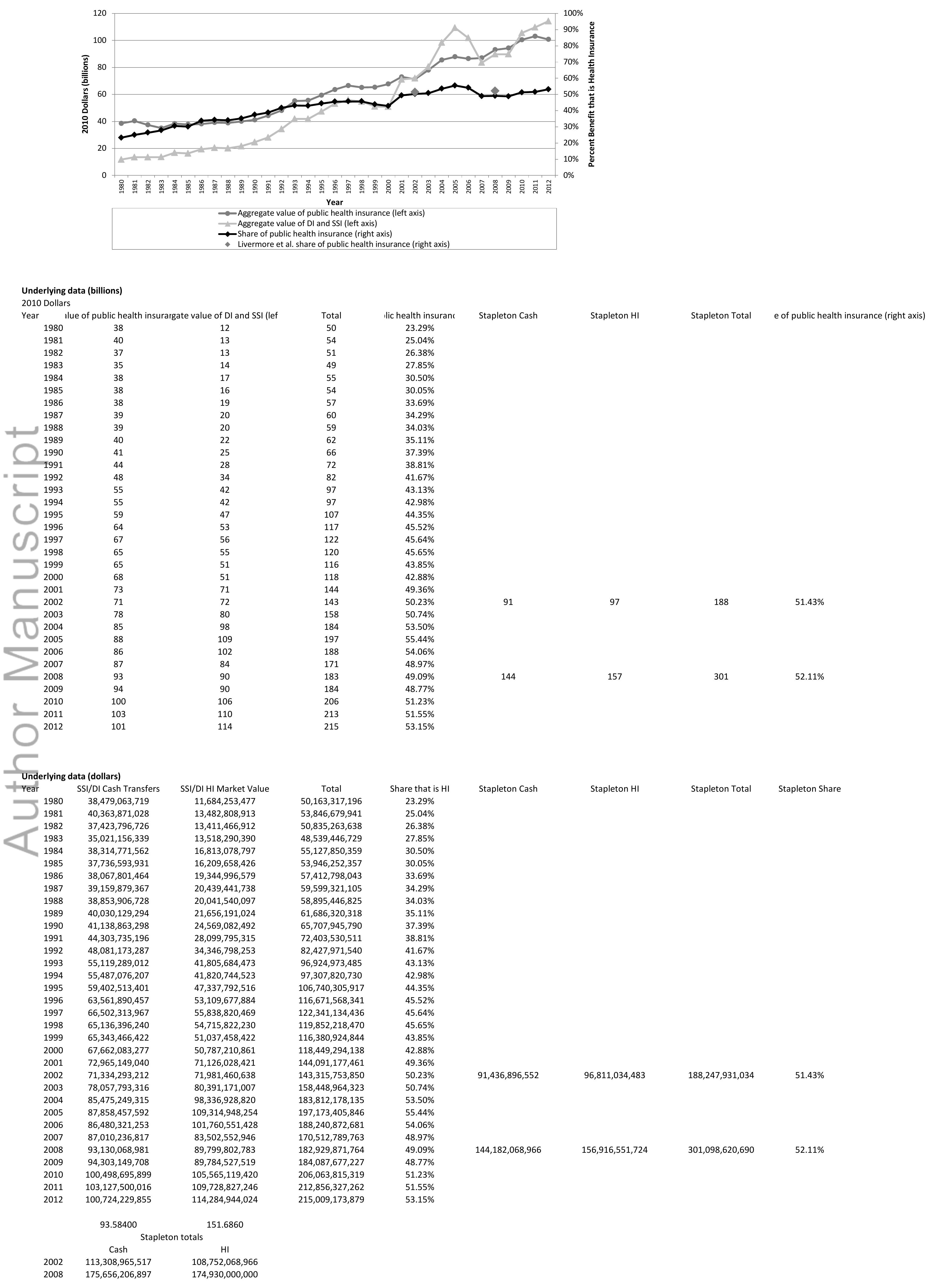
A - Trends in coverage rates

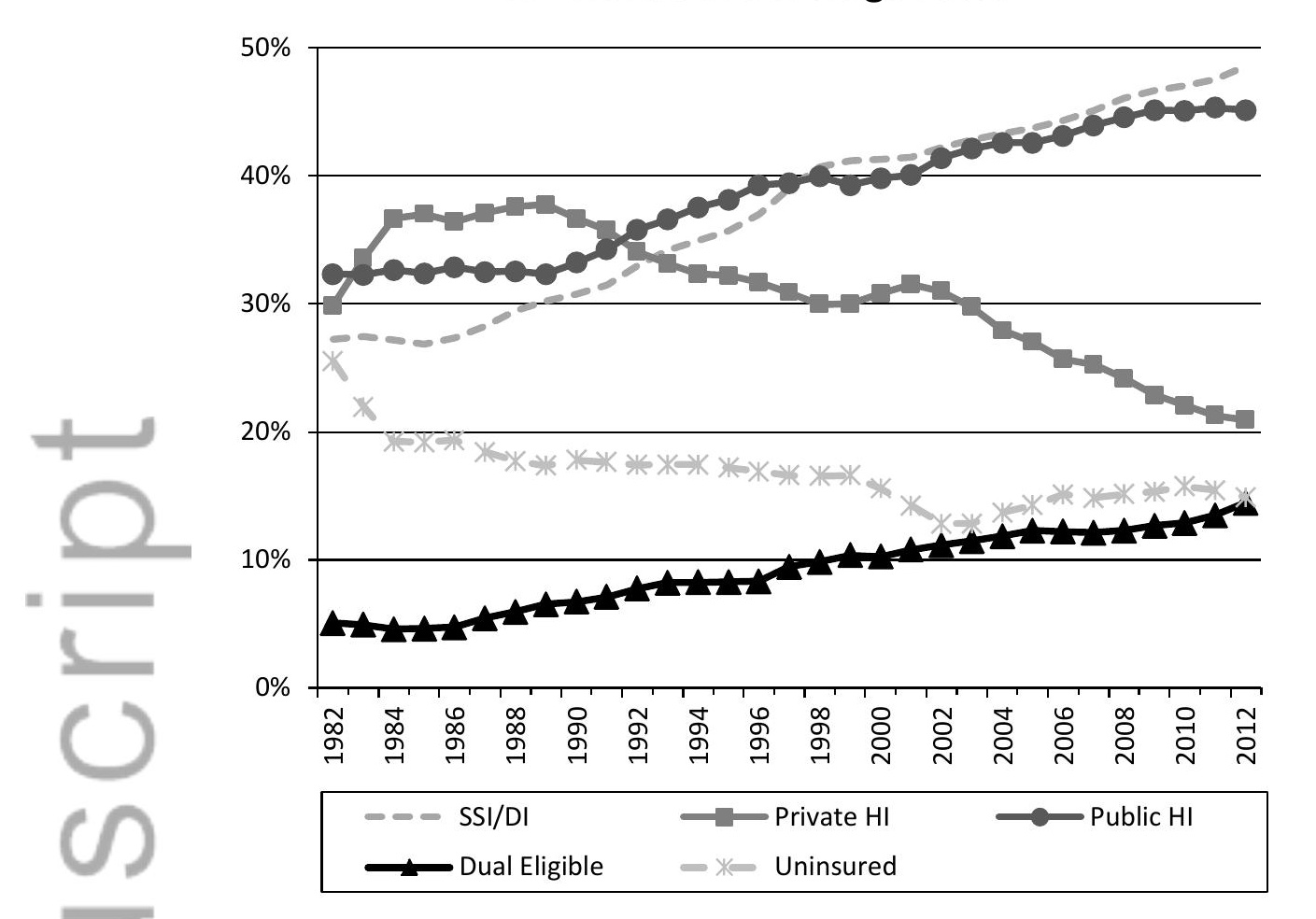

B - Values for those with coverage

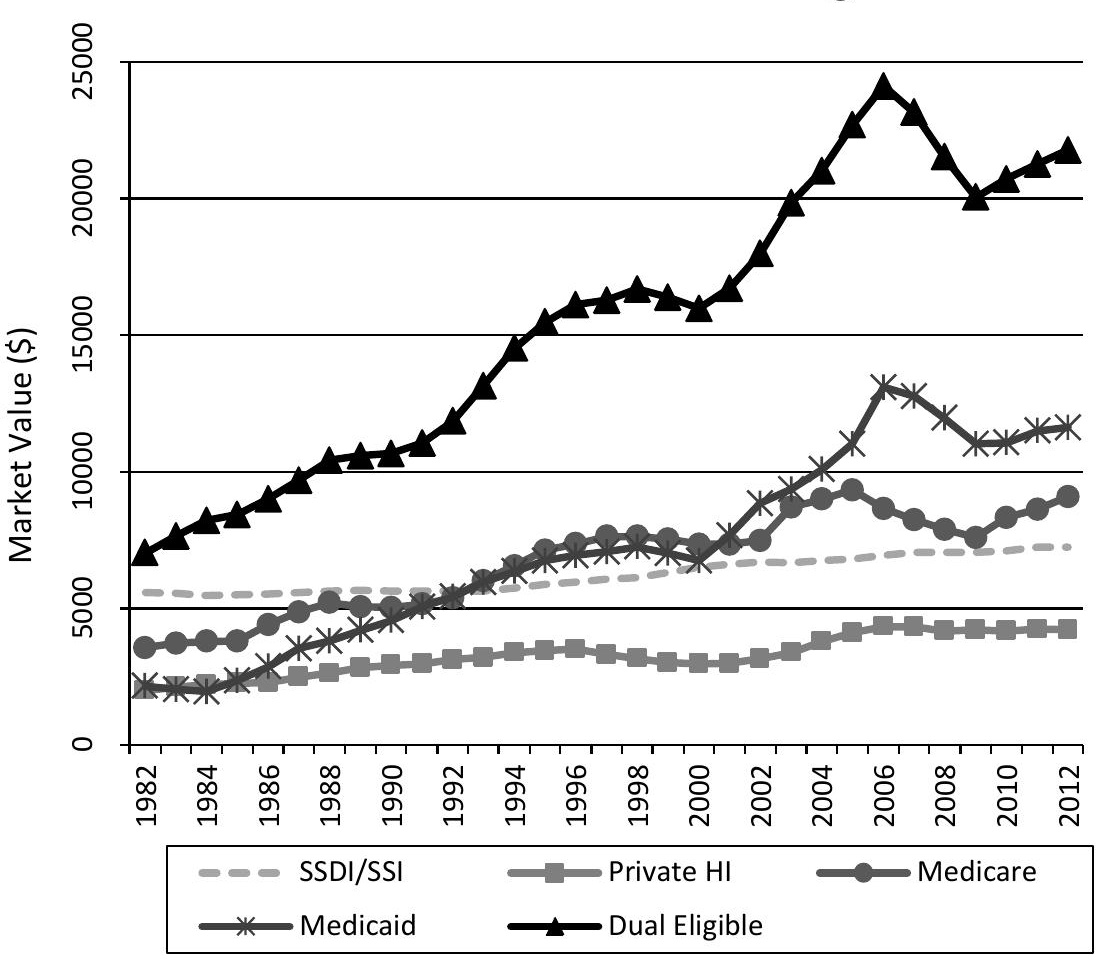

\section{Underlying data}

Panel A

SSI_DI_roll Public_HI_IDual_HI_rcPrivate_HI_Uninsured_roll $\begin{array}{llllll}1982 & 0.272325 & 0.323229 & 0.050764 & 0.298746 & 0.255218\end{array}$

$\begin{array}{lllllll}1983 & 0.274619 & 0.322402 & 0.049476 & 0.335683 & 0.219556\end{array}$

$\begin{array}{lllllll}1984 & 0.271481 & 0.326423 & 0.045731 & 0.366484 & 0.192485\end{array}$

$\begin{array}{llllllll} & 1985 & 0.268609 & 0.32362 & 0.046488 & 0.369949 & 0.19188\end{array}$

$\begin{array}{llllllll}1986 & 0.273139 & 0.328561 & 0.047589 & 0.363995 & 0.193349 \\ 1987 & 0.28252 & 0.32461 & 0.0546 & 0.370743 & 0.18309\end{array}$

$\begin{array}{lllllll}1987 & 0.282527 & 0.324676 & 0.0546 & 0.370743 & 0.184309\end{array}$

\begin{tabular}{lllllll}
1988 & 0.294199 & 0.325131 & 0.059384 & 0.375599 & 0.17704 \\
\hline & 1989 & 0.302005 & 0.323094 & 0.05342 & 0.377208 & 0.173603
\end{tabular}

$\begin{array}{lllllll}1 & 0.302005 & 0.323094 & 0.065342 & 0.377208 & 0.173603\end{array}$

\begin{tabular}{lllllll}
190.367327 & 0.332008 & 0.067374 & 0.366319 & 0.17805 \\
\hline
\end{tabular}

$\begin{array}{lllllll}1 & 19.314674 & 0.342283 & 0.071169 & 0.357524 & 0.176268\end{array}$

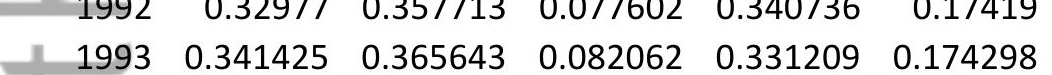

$\begin{array}{llllllll}1994 & 0.341425 & 0.365643 & 0.082062 & 0.331209 & 0.174298\end{array}$

$\begin{array}{llllllll}1994 & 0.349112 & 0.375129 & 0.082471 & 0.323099 & 0.174499\end{array}$

\begin{tabular}{llllllll}
\hline & 1996 & 0.3545 & 0.38098 & 0.082829 & 0.322046 & 0.171987
\end{tabular}

$\begin{array}{lllllll}1997 & 0.3668 & 0.392633 & 0.08323 & 0.31664 & 0.169109\end{array}$

$\begin{array}{lllllll}199 & 0.390048 & 0.394173 & 0.094796 & 0.308681 & 0.166085\end{array}$

$\begin{array}{llllllll}1999 & 0.4056 & 0.39299 & 0.098387 & 0.299395 & 0.165509\end{array}$

$\begin{array}{lllllll}1900 & 0.411675 & 0.392445 & 0.103603 & 0.29987 & 0.165956\end{array}$

$\begin{array}{lllllll}2001 & 0.41417 & 0.397833 & 0.102641 & 0.30793 & 0.155795\end{array}$

$\begin{array}{lllllll}2002 & 0.422005 & 0.413735 & 0.111384 & 0.30137 & 0.142558\end{array}$

$\begin{array}{lllllll}2003 & 0.42765 & 0.421352 & 0.11384 & 0.309696 & 0.128245\end{array}$

$\begin{array}{lllllll}2004 & 0.433029 & 0.421062 & 0.114853 & 0.297373 & 0.128399\end{array}$

$\begin{array}{lllllll}2005 & 0.43029 & 0.425483 & 0.11868 & 0.279065 & 0.136926\end{array}$

$\begin{array}{lllllll}2006 & 0.443334 & 0.430993 & 0.122096 & 0.256551 & 0.150963\end{array}$

$\begin{array}{llllllll}2007 & 0.450776 & 0.439162 & 0.121387 & 0.252518 & 0.148498\end{array}$

$\begin{array}{lllllll}2008 & 0.460436 & 0.445342 & 0.12296 & 0.241795 & 0.151365\end{array}$

$\begin{array}{llllllll}2009 & 0.466275 & 0.451042 & 0.126594 & 0.22881 & 0.153298 \\ 2010 & 0.470102 & 0.450429 & 0.129037 & 0.228412 & 0.15727\end{array}$

$\begin{array}{lllllll}2011 & 0.475126 & 0.450429 & 0.129037 & 0.228412 & 0.15727 \\ 20.452979 & 0.134961 & 0.212629 & 0.154311\end{array}$

$\begin{array}{llllll}2012 & 0.485203 & 0.450944 & 0.144598 & 0.209344 & 0.148822\end{array}$
Panel B

1983

1984

1985

1986

1987

1988

1989

1990

1991

1993

1994

1995

1996

1997

1998

1999

2001

2002

2003

ployer_roll
1984.677956
2123.761547
2189.759464
2263.722168
2277.454343
2475.901023
2635.134728
2809.73233
2909.893924
2967.850503
3121.274221
3189.963844
3380.260761
3449.08746
3491.837
3309.304904
3155.882536
3000.0805
2969.13614
2975.03461
3139.04073
3380.005854
3781.49065
4107.24913
4327.02327
4314.49735
4166.91551
4200.312679
4169.18267
4243.001067
4206.91625

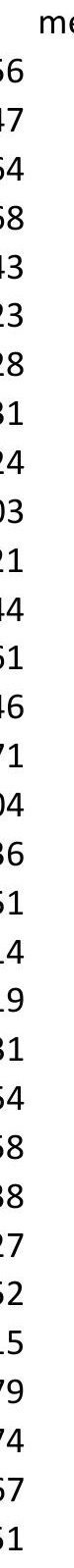

medicare_roll

medicaid_roll

dual_roll $3559.016426 \quad 2148.11621$

7021.930589 $\begin{array}{lll}3722.462808 & 2148.116217 & 7021.930589 \\ 3729184 & 7633.836227\end{array}$ $\begin{array}{lll}3785.861604 & 1951.793523 & 8216.045158\end{array}$ $\begin{array}{lll}3802.669026 & 2351.046324 & 8421.289846\end{array}$ $\begin{array}{lll}4402.858295 & 2855.678986 & 9005.829976\end{array}$ $\begin{array}{lll}4869.483622 & 3516.825926 & 9678.191395\end{array}$ $\begin{array}{lll}5203.305741 & 3802.766305 & 10418.3515\end{array}$ $\begin{array}{lll}5045.755678 & 4197.132524 & 10586.89137\end{array}$ $\begin{array}{lll}5023.464707 & 4551.39076 & 10661.4707\end{array}$ $\begin{array}{lll}5146.566054 & 5045.82694 & 11041.82065\end{array}$ $\begin{array}{lll}5381.187402 & 5418.28849 & 11843.02999\end{array}$ $\begin{array}{lll}5999.323871 & 5944.85356 & 13138.62058\end{array}$ $\begin{array}{lll}6545.938271 & 6340.27753 & 14513.05579\end{array}$ $\begin{array}{lll}7127.931829 & 6734.870215 & 15467.92129\end{array}$ $\begin{array}{lll}7355.449481 & 6929.640101 & 16101.36229\end{array}$ $\begin{array}{lll}7627.165499 & 7067.677956 & 16270.22695\end{array}$ $\begin{array}{lll}7628.36634 & 7239.388907 & 16681.79051\end{array}$ $\begin{array}{lll}7531.432916 & 7010.531009 & 16376.44972\end{array}$ $\begin{array}{lll}7339.86455 & 6733.95322 & 15978.93909\end{array}$ \begin{tabular}{lll}
7330.302983 & 7668.131424 & 16714.08432 \\
\hline 7882.877488 & 8855.179174 & 17968.1999
\end{tabular} $\begin{array}{lll}7482.877448 & 8845.179174 & 17968.19994\end{array}$ $\begin{array}{lll}7869.87725629 & 9350.298845 & 19843.21963\end{array}$ $\begin{array}{rrr}8985.180884 & 10078.26779 & 21008.74176 \\ 9318.556585 & 11016.2058 & 22880.64756\end{array}$ $\begin{array}{lll}9318.556585 & 11016.2058 & 22680.6479 \\ 864505767 & 13740.6664 & 2416.27156\end{array}$ $\begin{array}{lll}8645.05767 & 13090.6664 & 24116.27156 \\ 8240.021249 & 12749.01497 & 2314.3084\end{array}$ $\begin{array}{lll}8240.021249 & 13749.91497 & 23144.36084 \\ 7881.582057 & 11954.17459 & 21515.3406\end{array}$ $\begin{array}{lll}7881.582057 & 11954.17459 & 21515.34606 \\ 7582.092696 & 11019.23132 & 20042.7286\end{array}$ $\begin{array}{lll}7582.092696 & 11019.23132 & 20042.79286 \\ 8323.411483 & 11052.61315 & 20707.15501\end{array}$ $\begin{array}{lll}8323.411483 & 11052.61315 & 20707.15501 \\ 8612.01715 & 1149.101993 & 21258.69369\end{array}$ $\begin{array}{rrr}9079.062227 & 11609.98019 & 21774.7998\end{array}$ 
Figure 3. Trends in median size-adjusted income by income definition for working-age people with and without disabilities (1980-2012)
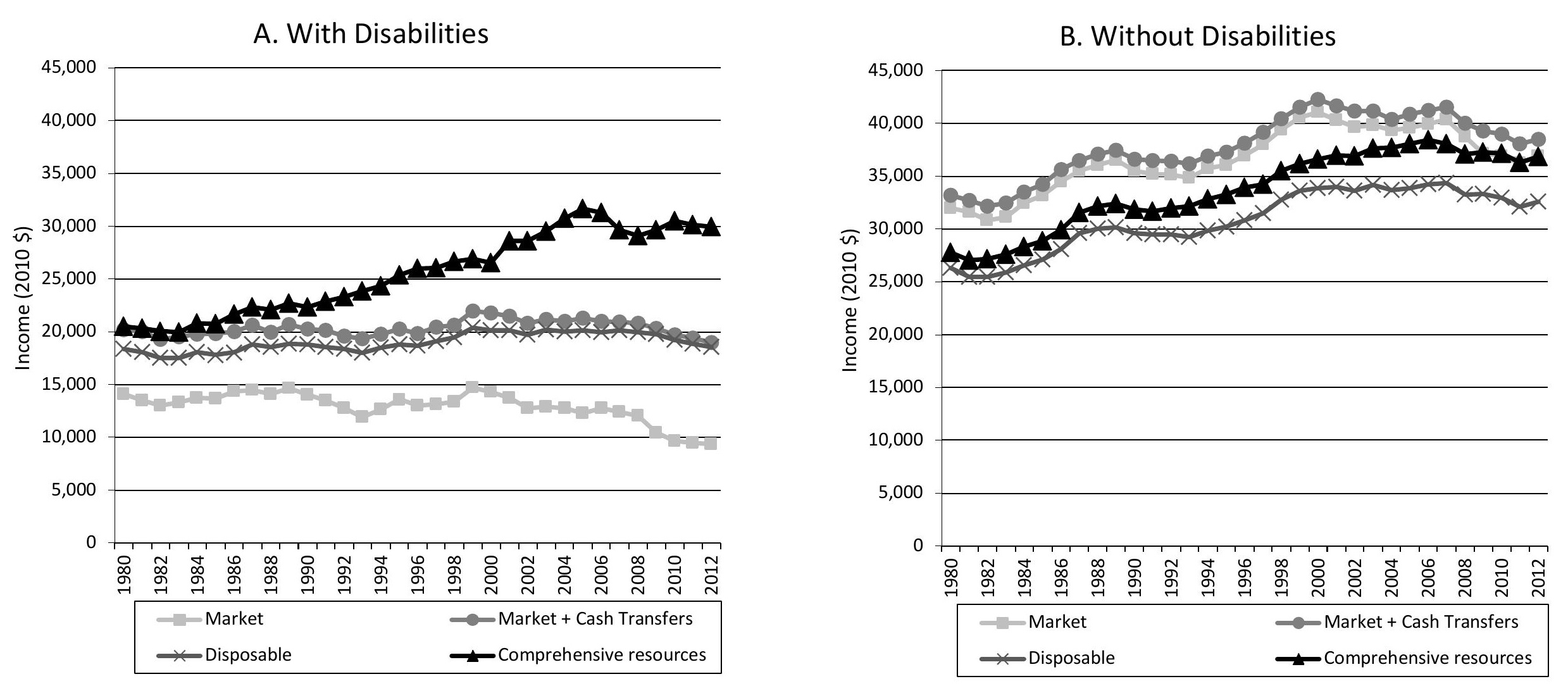

\begin{tabular}{|c|c|c|c|c|c|c|c|c|c|c|c|c|c|c|c|c|c|c|c|c|c|c|}
\hline \multicolumn{2}{|c|}{ PANEL A } & \\
\hline 20 & $\mathrm{TYPE}_{-}$ & & EQ_ & wgt_N & Market & Market $+C D$ & Disposab & & & & 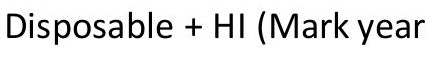 & PE & & & Writo & Market & Mark & & & & & 261700 \\
\hline & 1980 & 0 & 7975 & 10182213 & 14081.08 & 20218.22 & 18395.12 & 20508.58 & 19320.69 & 18916.49 & 18629.51 & 1980 & 0 & 100477 & $1.27 E+08$ & 31963.08 & 33161.95 & 26304.82 & 27764.15 & 27159.83 & 26733.77 & 26479.9 \\
\hline & 1981 & 0 & 7227 & 10356454 & 13496.21 & 19993 & 18045.22 & 20314.73 & 19100.51 & 18672.63 & 18374.26 & 1981 & 0 & 90511 & $1.29 E+08$ & 31592.78 & 32704.4 & 25483.84 & 27068.77 & 26549.04 & 25945.64 & 25686.91 \\
\hline & 1982 & 0 & 7054 & 10115399 & 12983.16 & 19285.91 & 17525.92 & 20042.15 & 18655.33 & 18201.81 & 17743.03 & 1982 & 0 & 91101 & $1.31 \mathrm{E}+08$ & 30812.37 & 32137.04 & 25447.26 & 27137.74 & 26733.18 & 25947.93 & 25676.17 \\
\hline & 1983 & 0 & 6999 & 10365064 & 13304.09 & 19538.48 & 17529.31 & 19978.45 & 18867.05 & 18236.52 & 17948.83 & 1983 & 0 & 90571 & $1.33 E+08$ & 31116.83 & 32446.24 & 25875.02 & 27614.43 & 27321.92 & 26396.25 & 26191.03 \\
\hline & 1984 & 0 & 7200 & 10957025 & 13764.04 & 19771.36 & 18077.11 & 20818.27 & 19380.68 & 18851.59 & 18724.23 & 1984 & 0 & 90563 & $1.33 E+08$ & 32457.58 & 33508.12 & 26544.41 & 28313.81 & 28055.8 & 27063.34 & 26994.92 \\
\hline & 1985 & 0 & 6856 & 10904731 & 13703.55 & 19817.96 & 17787.56 & 20745.22 & 19091.89 & 18614.28 & 18546.22 & 1985 & 0 & 88385 & $1.35 E+08$ & 33193.81 & 34243.8 & 27096.26 & 28847.95 & 28000.99 & 27625.85 & 27567.82 \\
\hline & 1986 & 0 & 6696 & 10882475 & 14320.64 & 19997.93 & 18031.38 & 21629.18 & 19178.42 & 18894.66 & 18632.44 & 1986 & 0 & 87403 & $1.37 E+08$ & 34489.73 & 35598.91 & 28079.46 & 29916.89 & 29034.48 & 28627.79 & 28495.54 \\
\hline & 1987 & 0 & 6462 & 10449961 & 14449.54 & 20610.99 & 18771.63 & 22329.93 & 20121.96 & 19780.88 & 19631.78 & 1987 & 0 & 87816 & $1.39 E+08$ & 35505.36 & 36499.54 & 29575.48 & 31564.17 & 30657.05 & 30217.39 & 30140.32 \\
\hline & 1988 & 0 & 6010 & ) 10449214 & 14071.65 & 19957.78 & 18520.08 & 22112.09 & 19784.77 & 19514.89 & 19433.37 & 1988 & 0 & 81405 & $1.4 \mathrm{E}+08$ & 36073.42 & 37105.2 & 30023.52 & 32150.71 & 31226.48 & 30679.28 & 30625.97 \\
\hline & 1989 & 0 & 6608 & 3 10716875 & 14632.72 & 20672.48 & 18851.17 & 22675.41 & 20507.86 & 20009.04 & 19739.6 & 1989 & 0 & 89215 & $1.41 E+08$ & 36535.75 & 37460.48 & 30154.08 & 32390.77 & 31436.38 & 30817.43 & 30694.47 \\
\hline & 1990 & 0 & 6630 & 10889478 & 14061.78 & 20260.22 & 18780.83 & 22334.8 & 20098.17 & 19701.75 & 19429.69 & 1990 & 0 & 88971 & $1.42 E+08$ & 35472.93 & 36614.77 & 29614.85 & 31842.67 & 30959.27 & 30292.69 & 30103.73 \\
\hline & 1991 & 0 & 6718 & 311345584 & 13519.97 & 20130.21 & 18535.35 & 22874.31 & 20331.5 & 19721.65 & 19459.75 & 1991 & 0 & 87348 & $1.43 E+08$ & 35206.15 & 36468.83 & 29456.86 & 31660.87 & 30828.53 & 30091.24 & 29957.61 \\
\hline & 1992 & 0 & 6854 & 11791088 & 12761.77 & 19593.55 & 18347.23 & 23317.19 & 20071.33 & 19543.7 & 19512.95 & 1992 & 0 & 86291 & $1.44 E+08$ & 35162.36 & 36411.36 & 29480.31 & 31983.32 & 31020.09 & 30213.34 & 30181.49 \\
\hline & 1993 & 0 & 6952 & 12753461 & 11886.28 & 19354.59 & 18008.76 & 23828.56 & 20089.2 & 19635.04 & 19959.85 & 1993 & 0 & 83035 & $1.46 E+08$ & 34862.45 & 36175.65 & 29205.32 & 32126.64 & 31097.01 & 30065.53 & 30251.02 \\
\hline & 1994 & 0 & 6913 & 12802024 & 12651.88 & 19740.79 & 18487.71 & 24308.08 & 20617.36 & 19997.09 & 20976.9 & 1994 & 0 & 82747 & $1.47 E+08$ & 35731.28 & 36875.34 & 29856.81 & 32831.83 & 31757.8 & 30679.51 & 31154.49 \\
\hline & 1995 & 0 & 6030 & 12713213 & 13583.85 & 20268.17 & 18821.12 & 25400.51 & 21036.06 & 20582.41 & 21915.66 & 1995 & 0 & 71993 & $1.49 E+08$ & 36031.18 & 37276.75 & 30208.5 & 33257.72 & 32216.86 & 31104.15 & 31731.08 \\
\hline & 1996 & 0 & 6229 & 13021746 & 13008.38 & 19833.84 & 18661.5 & 25993.81 & 20855.06 & 20630.76 & 23435.68 & 1996 & 0 & 72967 & $1.51 \mathrm{E}+08$ & 36938.94 & 38124.13 & 30804.1 & 33907.41 & 32873.92 & 31736.22 & 32848.36 \\
\hline & 1997 & 0 & 6054 & 12815057 & 13132.92 & 20419.59 & 19115.86 & 26059.45 & 21433.75 & 21035.49 & 24921.92 & 1997 & 0 & 73249 & $1.52 E+08$ & 37999.39 & 39180.89 & 31508.5 & 34229.04 & 33362.49 & 32316.35 & 33825.74 \\
\hline & 1998 & 0 & 5899 & 12565976 & 13380.12 & 20607.74 & 19449.91 & 26647.78 & 21776.21 & 21321.08 & 24735.01 & 1998 & 0 & 74035 & $1.55 E+08$ & 39424.28 & 40422.37 & 32788.75 & 35500.42 & 34639.87 & 33597.78 & 34823.59 \\
\hline & 1999 & 0 & 6081 & 12772428 & 14683.27 & 21941.27 & 20370.98 & 26870.48 & 22664.24 & 22208.89 & 24884.37 & 1999 & 0 & 75183 & $1.56 E+08$ & 40565.1 & 41548.98 & 33595.84 & 36166.23 & 35396.98 & 34331.61 & 35355.18 \\
\hline & 2000 & 0 & 5802 & 12628475 & 14267.96 & 21796.51 & 20162.38 & 26532.74 & 22550.79 & 21869.22 & 24068.87 & 2000 & 0 & 72671 & $1.58 \mathrm{E}+08$ & 41017.26 & 42232.45 & 33872 & 36596.88 & 35854.02 & 34692.27 & 35562.07 \\
\hline & 2001 & 0 & 9256 & 13457857 & 13723.27 & 21481.79 & 20127.43 & 28584.22 & 22827.77 & 22592.08 & 24901.17 & 2001 & 0 & 119993 & $1.62 E+08$ & 40325.97 & 41630.88 & 33962.38 & 36939.99 & 36068.18 & 34818.51 & 35609.48 \\
\hline & 2002 & 0 & 9188 & 313086547 & 12772.21 & 20794.92 & 19681.78 & 28619.22 & 22352.92 & 22132.39 & 24435.95 & 2002 & 0 & 120212 & $1.65 E+08$ & 39643.26 & 41155.95 & 33634.98 & 36873.35 & 35977.37 & 34590.92 & 35455.54 \\
\hline & 2003 & 0 & 9544 & 14188979 & 12860.53 & 21184.91 & 20175.57 & 29508.54 & 23051.23 & 22700.65 & 26183.87 & 2003 & 0 & 118208 & $1.66 \mathrm{E}+08$ & 39841.49 & 41140.21 & 34158.71 & 37640.35 & 36799.39 & 35146.3 & 36484.67 \\
\hline & 2004 & 0 & 9461 & 14536005 & 12741.72 & 21002.79 & 19988.67 & 30752.81 & 23073.23 & 22943.5 & 26750.32 & 2004 & 0 & 116471 & $1.68 \mathrm{E}+08$ & 39336.41 & 40344.08 & 33672.72 & 37686.25 & 36673.24 & 34842.89 & 36216.82 \\
\hline & 2005 & 0 & 9441 & 14790086 & 12284.93 & 21274.76 & 20144.5 & 31646.13 & 23276.17 & 23322.31 & 27892.17 & 2005 & 0 & 115877 & $1.7 E+08$ & 39553.54 & 40836.92 & 33883.35 & 38060.02 & 37104.69 & 35104.13 & 36698.57 \\
\hline & 2006 & 0 & 8830 & 14131178 & 12765.96 & 20971.33 & 19977.4 & 31280.44 & 23148.53 & 23342.23 & 28344.06 & 2006 & 0 & 115542 & $1.72 E+08$ & 39923.16 & 41203.15 & 34198.47 & 38453.14 & 37454.13 & 35368.56 & 37256.78 \\
\hline & 2007 & 0 & 8849 & 14099175 & 12413.79 & 20924.48 & 20159.22 & 29643.86 & 23402.08 & 22632.22 & 26526.75 & 2007 & 0 & 115750 & $1.74 E+08$ & 40344.83 & 41529.8 & 34315.65 & 38085.8 & 37534.41 & 35388.54 & 36908.88 \\
\hline & 2008 & 0 & 9348 & 3 15217156 & 12028.94 & 20820.68 & 19948.21 & 29072.25 & 23445.49 & 22369.8 & 27690.07 & 2008 & 0 & 116387 & $1.74 E+08$ & 38708.21 & 40011.24 & 33232.99 & 37078.42 & 36658.74 & 34390.91 & 36556.17 \\
\hline & 2009 & 0 & 9487 & 15125943 & 10428 & 20307 & 19740.18 & 29649.69 & 23370.2 & 22523.38 & 296 & 2009 & 0 & 117699 & $1.75 E+08$ & 37118.73 & 39284.64 & 33305.19 & 37240.27 & 36664.75 & 34434.62 & 37240.27 \\
\hline & 2010 & 0 & 9325 & 15560098 & 9682.44 & 19686.14 & 19209.77 & 30505.12 & 22803.37 & 22404.29 & 29839.29 & 2010 & 0 & 115489 & $1.76 E+08$ & 36891.01 & 38956.31 & 32918.27 & 37159.25 & 36349.13 & 34139.69 & 36906.95 \\
\hline & 2011 & 0 & $944{ }^{\circ}$ & 15777357 & 9448.408 & 19414.03 & 18839.78 & 0136.62 & 22697.08 & 2041.79 & 1131.52 & 2011 & 0 & 112809 & $1.77 \mathrm{E}+08$ & 36212.73 & 38047 & 32099.52 & 36300.88 & 35702.4 & 33304.2 & .13 \\
\hline & 2012 & 0 & 9398 & 315800290 & 9341.637 & 18952.6 & 18548.01 & 29923.73 & 22421.43 & 21788.13 & 29083.07 & 2012 & 0 & 112878 & $1.78 \mathrm{E}+08$ & 36887.9 & 38500.22 & 32561.18 & 36836.85 & 36217.69 & 33742.27 & 36484.76 \\
\hline
\end{tabular}


et Value, CPI-MC Index)

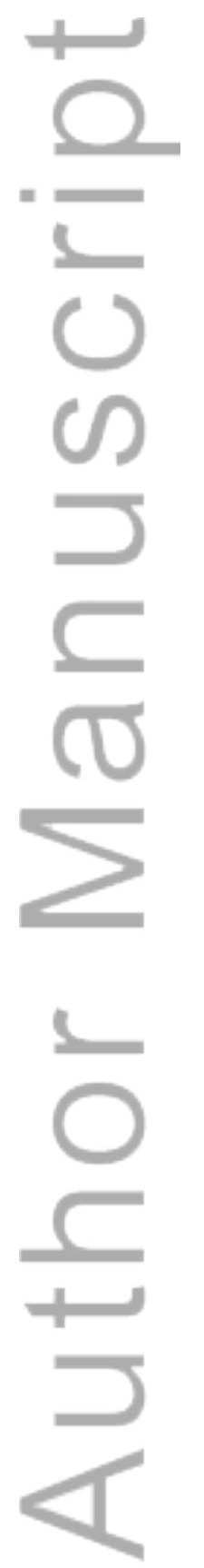

This article is protected by copyright. All rights reserved. 


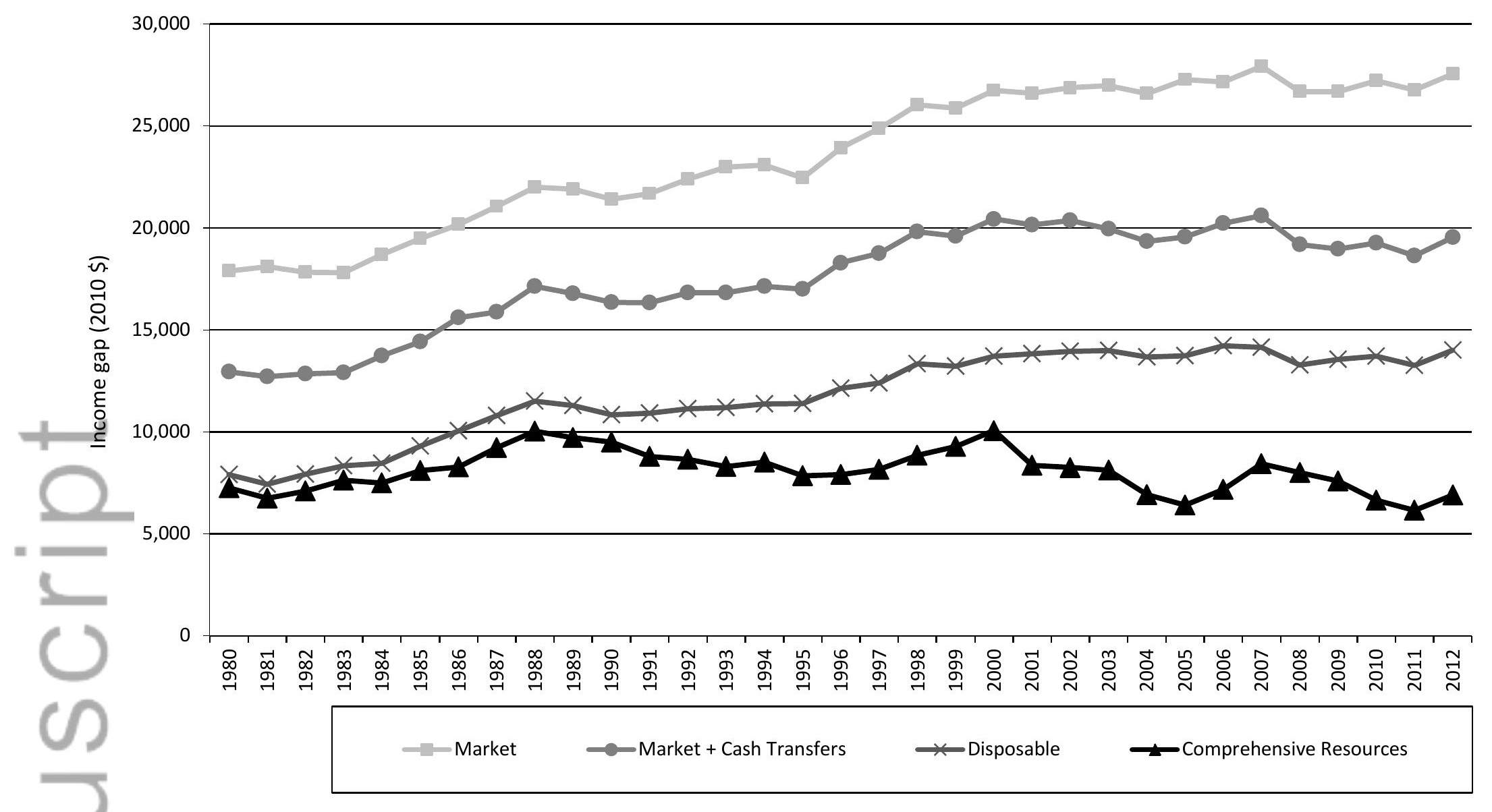

year Market Market + C Disposable Compreheı Disposable Disposable Disposable + HI (Market Value, CPI-MC Index) $\begin{array}{llllllll}1980 & 17882.01 & 12943.73 & 7909.7 & 7255.578 & 7839.136 & 7817.289 & 7850.388\end{array}$ $\begin{array}{lllllllll}1981 & 18096.57 & 12711.41 & 7438.616 & 6754.046 & 7448.537 & 7273.001 & 7312.649\end{array}$ $\begin{array}{lllllllll}1982 & 17829.21 & 12851.14 & 7921.338 & 7095.589 & 8077.848 & 7746.121 & 7933.133\end{array}$ $\begin{array}{llllllll}1983 & 17812.74 & 12907.76 & 8345.713 & 7635.971 & 8454.874 & 8159.733 & 8242.202\end{array}$ $\begin{array}{lllllllll}1984 & 18693.54 & 13736.76 & 8467.304 & 7495.545 & 8675.121 & 8211.747 & 8270.691\end{array}$ $\begin{array}{lllllllll}1985 & 19490.27 & 14425.85 & 9308.697 & 8102.729 & 8909.107 & 9011.576 & 9021.6\end{array}$ $\begin{array}{lllllllll}1986 & 20169.09 & 15600.99 & 10048.08 & 8287.712 & 9856.058 & 9733.131 & 9863.103\end{array}$ $\begin{array}{llllllll}1987 & 21055.81 & 15888.55 & 10803.85 & 9234.237 & 10535.09 & 10436.51 & 10508.54\end{array}$ $\begin{array}{llllllll}1988 & 22001.78 & 17147.42 & 11503.44 & 10038.62 & 11441.71 & 11164.4 & 11192.59\end{array}$ $\begin{array}{llllllll}1989 & 21903.03 & 16788.01 & 11302.91 & 9715.361 & 10928.52 & 10808.39 & 10954.87\end{array}$ $\begin{array}{llllllll}1990 & 21411.14 & 16354.56 & 10834.02 & 9507.867 & 10861.1 & 10590.94 & 10674.04\end{array}$ $\begin{array}{llllllll}1991 & 21686.18 & 16338.62 & 10921.51 & 8786.552 & 10497.02 & 10369.59 & 10497.86\end{array}$ $\begin{array}{lllllllll}1992 & 22400.59 & 16817.81 & 11133.08 & 8666.134 & 10948.76 & 10669.64 & 10668.53\end{array}$ $\begin{array}{llllllll}1993 & 22976.16 & 16821.05 & 11196.57 & 8298.086 & 11007.82 & 10430.49 & 10291.16\end{array}$ $\begin{array}{lllllllll}1994 & 23079.41 & 17134.55 & 11369.1 & 8523.751 & 11140.44 & 10682.42 & 10177.59\end{array}$ $\begin{array}{llllllll}1995 & 22447.33 & 17008.58 & 11387.38 & 7857.214 & 11180.8 & 10521.74 & 9815.419\end{array}$ $\begin{array}{llllllll}1996 & 23930.56 & 18290.29 & 12142.6 & 7913.6 & 12018.85 & 11105.46 & 9412.681\end{array}$ $\begin{array}{lllllllll}1997 & 24866.47 & 18761.3 & 12392.64 & 8169.582 & 11928.74 & 11280.86 & 8903.824\end{array}$ $\begin{array}{lllllllll}1998 & 26044.17 & 19814.63 & 13338.84 & 8852.647 & 12863.66 & 12276.7 & 10088.58\end{array}$ $\begin{array}{lllllllll}1999 & 25881.83 & 19607.71 & 13224.86 & 9295.745 & 12732.74 & 12122.72 & 10470.8\end{array}$ $\begin{array}{llllllll}2000 & 26749.3 & 20435.94 & 13709.61 & 10064.14 & 13303.24 & 12823.05 & 11493.2\end{array}$ $\begin{array}{lllllllll}2001 & 26602.7 & 20149.1 & 13834.95 & 8355.769 & 13240.42 & 12226.43 & 10708.31\end{array}$ $\begin{array}{lllllllll}2002 & 26871.06 & 20361.03 & 13953.2 & 8254.13 & 13624.44 & 12458.53 & 11019.59\end{array}$ $\begin{array}{llllllll}2003 & 26980.97 & 19955.3 & 13983.14 & 8131.808 & 13748.15 & 12445.65 & 10300.79\end{array}$ $\begin{array}{lllllllll}2004 & 26594.69 & 19341.29 & 13684.05 & 6933.436 & 13600.01 & 11899.39 & 9466.501\end{array}$ $\begin{array}{lllllllll}2005 & 27268.61 & 19562.16 & 13738.84 & 6413.892 & 13828.52 & 11781.82 & 8806.401\end{array}$ $\begin{array}{lllllllll}2006 & 27157.2 & 20231.83 & 14221.07 & 7172.704 & 14305.61 & 12026.33 & 8912.726\end{array}$ $\begin{array}{lllllllll}2007 & 27931.03 & 20605.32 & 14156.43 & 8441.932 & 14132.33 & 12756.32 & 10382.13\end{array}$ $\begin{array}{lllllllll}2008 & 26679.27 & 19190.56 & 13284.78 & 8006.172 & 13213.26 & 12021.11 & 8866.1\end{array}$ $\begin{array}{lllllllll}2009 & 26690.73 & 18977.64 & 13565.01 & 7590.579 & 13294.55 & 11911.24 & 7590.579\end{array}$ $\begin{array}{llllllll}2010 & 27208.57 & 19270.16 & 13708.5 & 6654.121 & 13545.76 & 11735.4 & 7067.662\end{array}$ $\begin{array}{lllllllll}2011 & 26764.32 & 18632.97 & 13259.74 & 6164.256 & 13005.32 & 11262.41 & 5609.611\end{array}$ $\begin{array}{llllllll}2012 & 27546.26 & 19547.62 & 14013.17 & 6913.12 & 13796.26 & 11954.15 & 7401.69\end{array}$ 
Figure 5. Share of All Working Aged Persons who have Disabilities in Trough Year Size-adjusted Resource Quintiles, based on Comprehensive Resources plus the
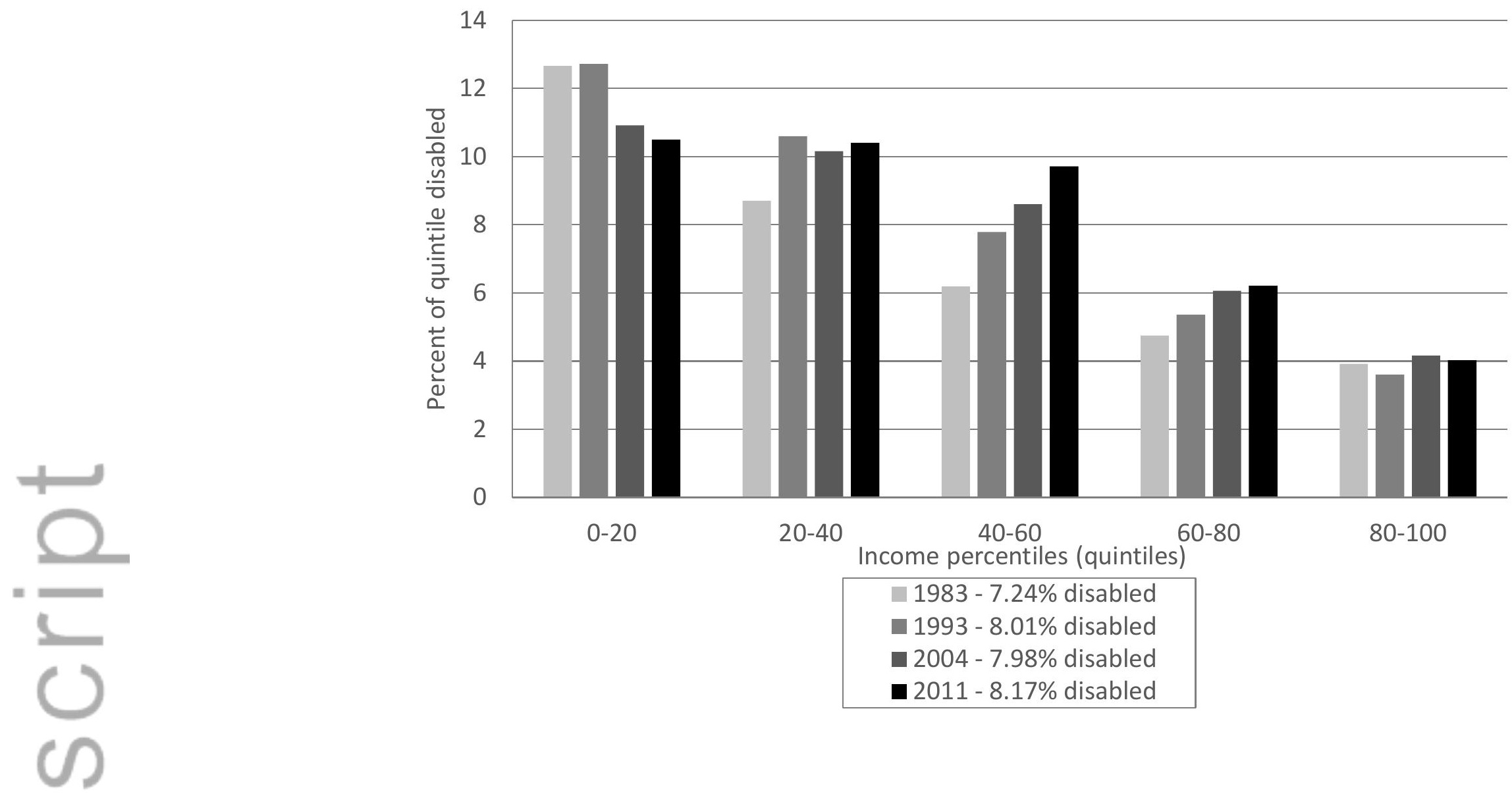

$0-20 \quad 20-40 \quad 40-60 \quad 60-80 \quad 80-100$

$\begin{array}{lllllll}1983-7.24 & 12.65686 & 8.702672 & 6.189953 & 4.748726 & 3.917459\end{array}$

$\begin{array}{lllllll}1993-8.01 & 12.72092 & 10.60307 & 7.788765 & 5.360698 & 3.604127\end{array}$

$\begin{array}{lllllll}2004-7.98 & 10.9116 & 10.16212 & 8.602755 & 6.066175 & 4.165454\end{array}$

$\begin{array}{llllll}2011-8.17 & 10.49241 & 10.40458 & 9.716143 & 6.207426 & 4.022183\end{array}$

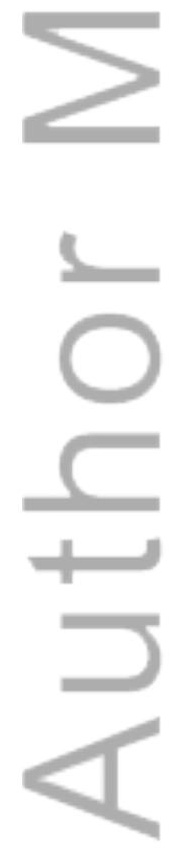


Value of Health Insurance

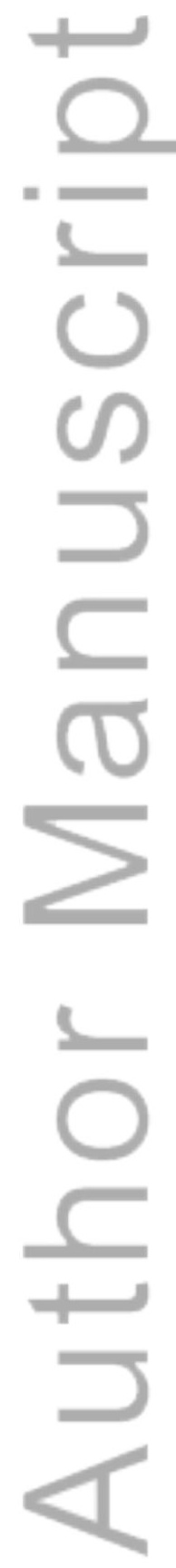

This article is protected by copyright. All rights reserved. 
Appendix Figure $1 A$ - Trends in public and private health insurance coverage and disability-based cash transfers and their value for working-age peo,

A - Trends in coverage rates

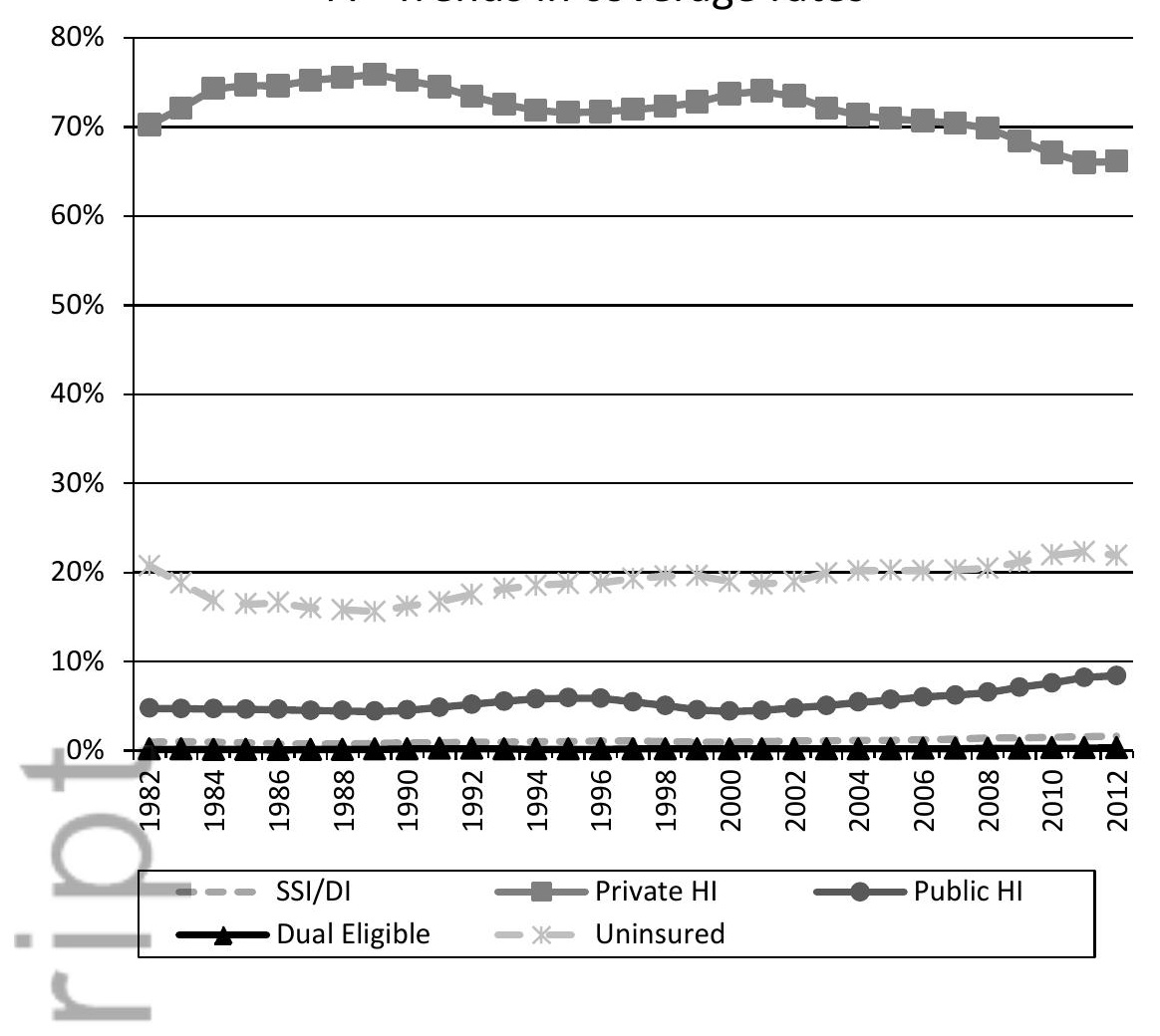

B - Values for those with coverage

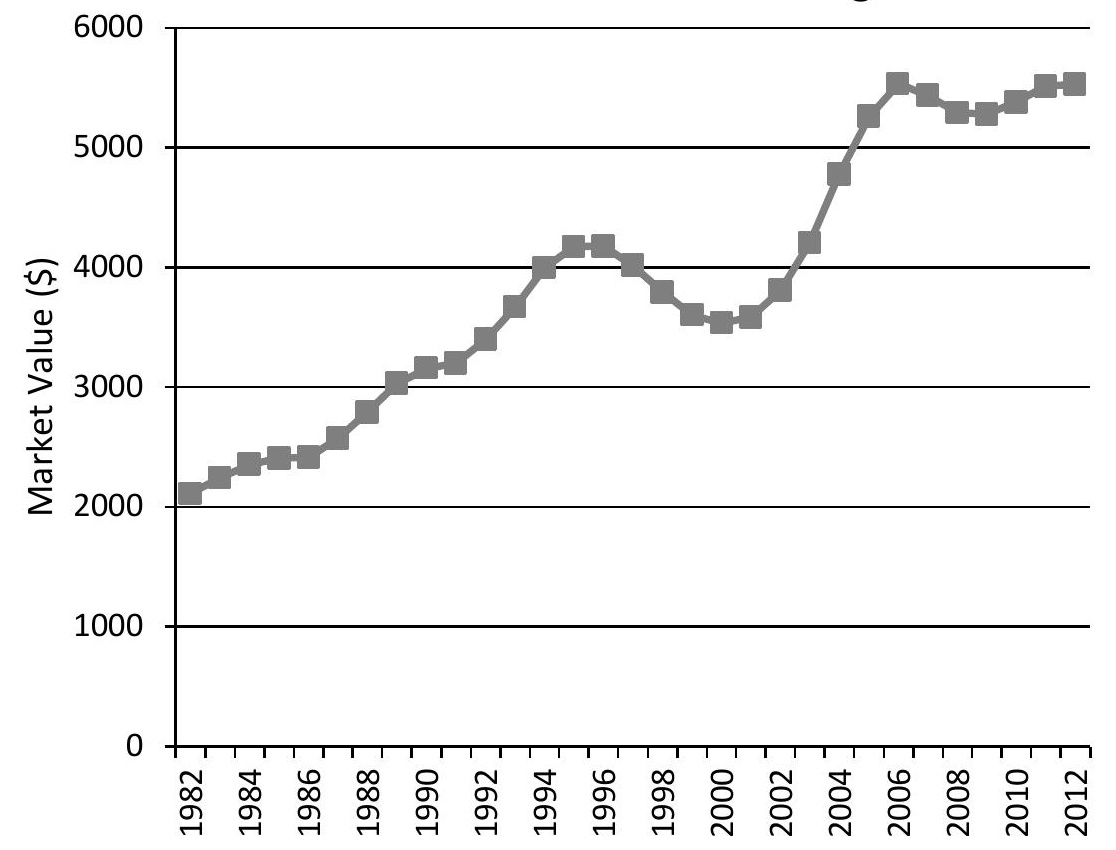

- Private HI
Panel A

year
Dual Eligible Private $\mathrm{HI} \quad$ Uninsured

0.0016215150 .702098359

$0.001546514 \quad 0.720783742$

$0.001348681 \quad 0.742477062$

$0.001083744 \quad 0.746613947$

$0.000952621 \quad 0.745664677$

$0.001097649 \quad 0.751896897$

$0.001453456 \quad 0.755171113$

$0.001719974 \quad 0.758480816$

$0.002104367 \quad 0.751852225$

$0.002185197 \quad 0.744945419$

$0.002402452 \quad 0.733917559$

$0.00207621 \quad 0.725078792$

$0.001732243 \quad 0.718320578$

$0.001579164 \quad 0.715924671$

$0.001640993 \quad 0.716732026$

$0.001817792 \quad 0.719242834$

$0.001791898 \quad 0.722473159$

$0.001808234 \quad 0.727510633$

$0.001867933 \quad 0.736603796$

$0.001826863 \quad 0.7396432$

$0.001875991 \quad 0.734197219$

$0.001961357 \quad 0.720823664$

$0.002142961 \quad 0.712898048$

$0.002150645 \quad 0.708895884$

$0.002205525 \quad 0.706584971$

0.0022177620 .703692676

$0.002512342 \quad 0.698464828$

$0.002613903 \quad 0.684003216$

$0.002906388 \quad 0.670484026$

$0.002980513 \quad 0.660063735$

$0.003391992 \quad 0.660922364$
0.207187185

0.187784571

0.168206439

0.164517104

0.165940238

0.160307306

0.15801777

0.155887531

0.161972557

0.166946984

0.175258796

0.181753375

0.185490249

0.18752005

0.188238797

0.192980143

0.195744428

0.196294468

0.189755429

0.186633987

0.189568049

0.199011031

0.201687419

0.20211842

0.201732221

0.202651448

0.204475104

0.211764311

0.219419098

0.223076208

0.219080332
Panel B

year Private $\mathrm{HI}$

$1982 \quad 2110.085$

$1983 \quad 2245.6$

$1984 \quad 2353.659$

$1985 \quad 2409.12$

$1986 \quad 2412.115$

$1987 \quad 2571.456$

$1988 \quad 2790.5$

$1989 \quad 3030.03$

$1990 \quad 3156.129$

19913199.798

$1992 \quad 3397.476$

$1993 \quad 3669.423$

$1994 \quad 3996.405$

19954171.193

$1996 \quad 4177.275$

19974015.753

$1998 \quad 3794.487$

$1999 \quad 3602.29$

$2000 \quad 3535.469$

$2001 \quad 3583.78$

$2002 \quad 3806.595$

20034204.566

$2004 \quad 4776.757$

$2005 \quad 5258.582$

$2006 \quad 5532.277$

$2007 \quad 5432.269$

$2008 \quad 5292.375$

$2009 \quad 5276.319$

$2010 \quad 5378.378$

20115512.439

$2012 \quad 5527.768$ 
ple without disabilities (1980-2012)

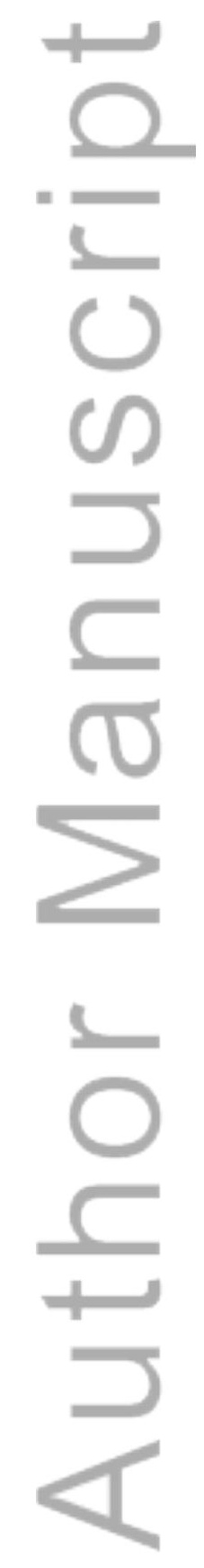

This article is protected by copyright. All rights reserved. 
Table 1. Trends in the share of gross mean resources including the value of health insurance by income source for working-age people with and $u$

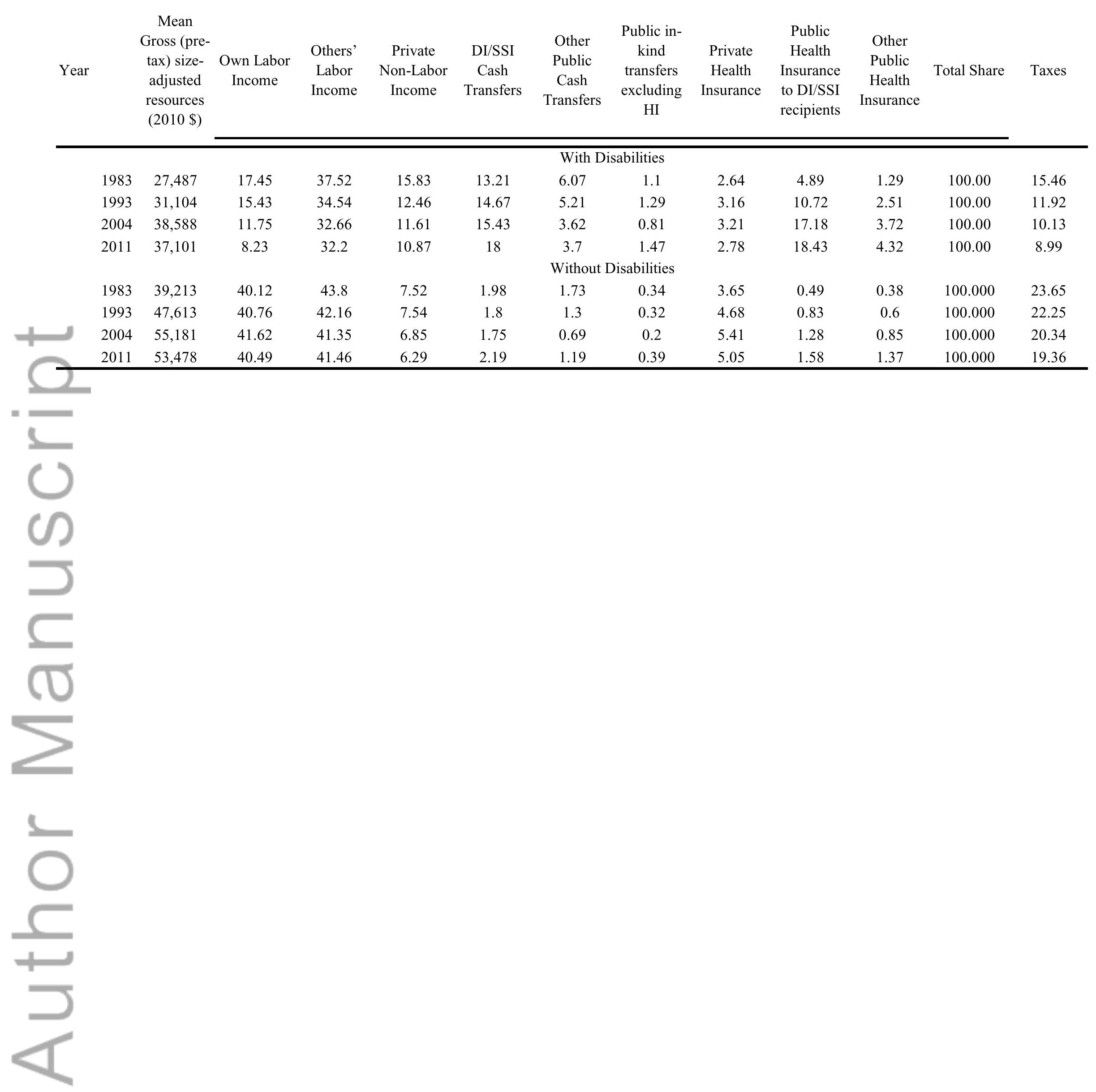


vithout disabilities

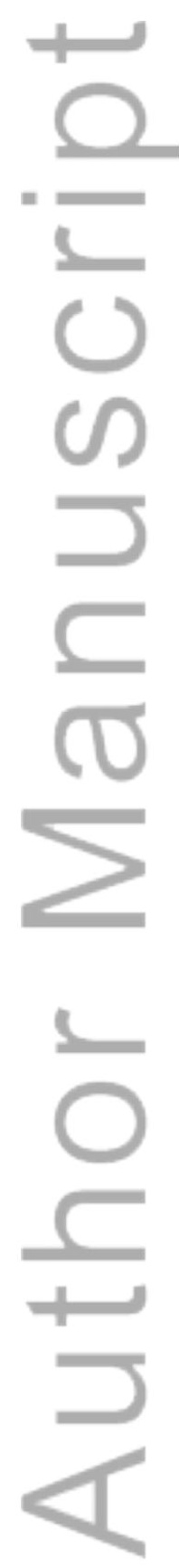

This article is protected by copyright. All rights reserved. 
Table 2. Comparison of the Median Estimated Value of Government Provided Health Insurance Policies Under

\begin{tabular}{lrrr}
$\begin{array}{r}\text { Number of } \\
\text { people with } \\
\text { work }\end{array}$ & $\begin{array}{r}\text { Median value } \\
\text { with rating for } \\
\text { pre-existing } \\
\text { limitations }\end{array}$ & $\begin{array}{r}\text { Median value } \\
\text { without rating } \\
\text { fonditions (Pre- } \\
\text { ACA) }(2010 \$)\end{array}$ & $\begin{array}{r}\text { conditions } \\
\text { (Post-ACA) } \\
(2010 \$)\end{array}$ \\
\hline Medicare & $3,085,841$ & 9,459 & 3,232 \\
Medicaid & $4,013,270$ & 10,770 & 3,470 \\
Dual-Eligible & $2,476,503$ & 22,115 & 3,470 \\
\hline
\end{tabular}

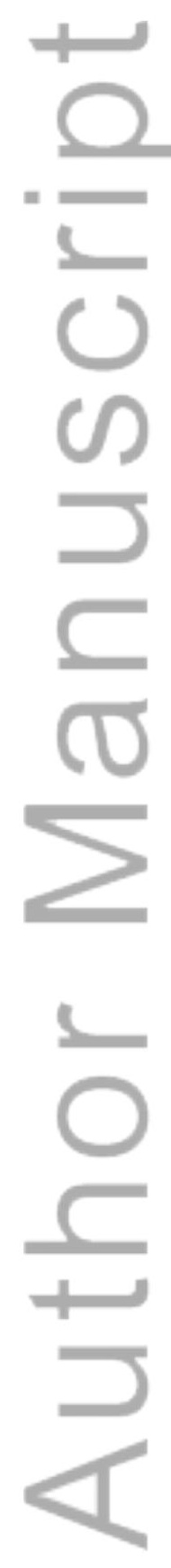

This article is protected by copyright. All rights reserved. 
the Pre- and Post-ACA Risk-Pools

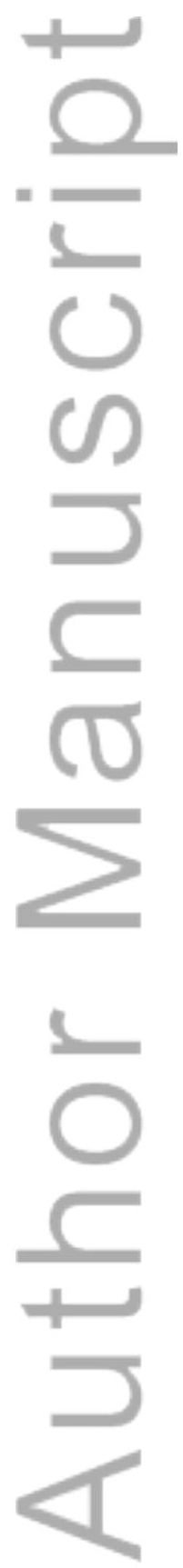

This article is protected by copyright. All rights reserved. 
Appendix Table 1A. Demographic Characteristics of People with and without Disabilities

\begin{tabular}{|c|c|c|c|c|c|c|c|c|c|c|}
\hline Year & $\mathrm{N}$ & Weighted N & Age & Male & White & Full Time & Part Time & Householder & Married & $\begin{array}{l}\text { Receive } \\
\text { SSI/DI }\end{array}$ \\
\hline \multicolumn{11}{|c|}{ Panel A - Without Disabilities } \\
\hline 1983 & 90,571 & $132,735,786$ & 36.75 & 0.49 & 0.83 & 0.48 & 0.33 & 0.78 & 0.73 & 0.01 \\
\hline 1993 & 83,035 & $146,354,650$ & 37.67 & 0.49 & 0.79 & 0.55 & 0.3 & 0.77 & 0.68 & 0.01 \\
\hline 2004 & 116,471 & $167,580,422$ & 39.37 & 0.49 & 0.74 & 0.59 & 0.25 & 0.77 & 0.64 & 0.01 \\
\hline 2011 & 112,809 & $177,367,748$ & 39.96 & 0.49 & 0.71 & 0.54 & 0.25 & 0.73 & 0.61 & 0.02 \\
\hline \multicolumn{11}{|c|}{ Panel B - With Disabilities } \\
\hline 1983 & 6,999 & $10,365,064$ & 46.92 & 0.51 & 0.79 & 0.13 & 0.22 & 0.8 & 0.61 & 0.27 \\
\hline 1993 & 6,952 & $12,753,461$ & 45.41 & 0.52 & 0.73 & 0.11 & 0.24 & 0.76 & 0.53 & 0.35 \\
\hline 2004 & 9,461 & $14,536,005$ & 46.85 & 0.49 & 0.71 & 0.09 & 0.18 & 0.75 & 0.46 & 0.44 \\
\hline 2011 & 9,449 & $15,777,357$ & 48.37 & 0.49 & 0.7 & 0.06 & 0.16 & 0.75 & 0.44 & 0.48 \\
\hline
\end{tabular}

$=$
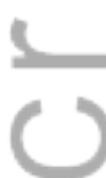

0

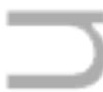

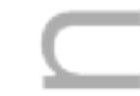

రে

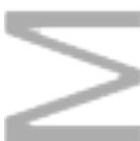

1
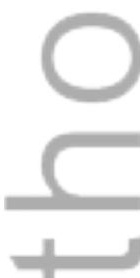

$+2$

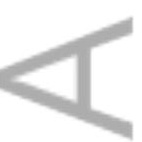

This article is protected by copyright. All rights reserved. 


\section{University Library}

\section{- M M N E R VA A gateway to Melbourne's research publications}

Minerva Access is the Institutional Repository of The University of Melbourne

Author/s:

Burkhauser, RV;Larrimore, J;Lyons, S

Title:

MEASURING HEALTH INSURANCE BENEFITS: THE CASE OF PEOPLE WITH DISABILITIES

Date:

2017-07-01

Citation:

Burkhauser, R. V., Larrimore, J. \& Lyons, S. (2017). MEASURING HEALTH INSURANCE BENEFITS: THE CASE OF PEOPLE WITH DISABILITIES. CONTEMPORARY ECONOMIC POLICY, 35 (3), pp.439-456. https://doi.org/10.1111/coep.12213.

Persistent Link:

http://hdl.handle.net/11343/292208 